

\section{A}

\section{Enfoque y alcance}

La Revista de Arquitectura (ISSN 1657-0308 Impresa y E-ISSN 2357-626X en línea) es una publicación seriada de acceso abierto, arbitrada mediante revisión por pares (doble ciego) e indexada, en donde se publican resultados de investigación originales e inéditos.

Está dirigida a la comunidad académica y profesional de las áreas afines a la disciplina. Es editada por la Facultad de Diseño y el Centro de Investigaciones (CIFAR) de la Universidad Católica de Colombia en Bogotá (Colombia).

La principal área científica a la que se adscribe la Revista de Arquitectura según la OCDE es:

Gran área: 6. Humanidades

Área: 6.D. Arte

Disciplina: 6D07. Arquitectura y Urbanismo

También se publican artículos de las disciplinas como 2A02, Ingeniería arquitectónica; 5G03, Estudios urbanos (planificación y desarrollo); 6D07, Diseño.

Los objetivos de la Revista de Arquitectura son:

- Promover la divulgación y difusión del conocimiento generado a nivel local, nacional e internacional

- Conformar un espacio para la construcción de comunidades académicas y la discusión en torno a las secciones definidas.

- Fomentar la diversidad institucional y geográfica de los autores que participan en la publicación.

- Potenciar la discusión de experiencias e intercambios científicos entre investigadores y profesionales.

- Contribuir a la visión integral de la arquitectura, por medio de la concurrencia y articulación de las secciones mediante la publicación de artículos de calidad.

- Publicar artículos originales e inéditos que han pasado por revisión de pares, para asegurar que se cumplen las normas éticas, de calidad, validez científica, editorial e investigativa.

- Fomentar la divulgación de las investigaciones y actividades desarrolladas en la Universidad Católica de Colombia.
Palabras clave de la Revista de Arquitectura: arquitectura, diseño, educación arquitectónica, proyecto y construcción, urbanismo.

Idiomas de publicación: español, inglés, portugués y francés.

Título abreviado: Rev. Arquit.

Titulo corto: RevArq

\section{Políticas de sección}

La revista se estructura en tres secciones correspondientes a las líneas de investigación activas y aprobadas por la institución, y dos complementarias, que presentan dinámicas propias de la Facultad de Diseño y las publicaciones relacionadas con la disciplina.

CULTURA Y ESPACIO URBANO. En esta sección se publican los artículos que se refieren a fenómenos sociales en relación con el espacio urbano, atendiendo aspectos de la historia, el patrimonio cultural y físico, y la estructura formal de las ciudades y el territorio.

Proyecto ARQUitectónico y URBANO. En esta sección se presentan artículos sobre el concepto de proyecto, entendido como elemento que define y orienta las condiciones proyectuales que devienen en los hechos arquitectónicos o urbanos, y la forma como estos se convierten en un proceso de investigación y nuevo de conocimiento. También se presentan proyectos que sean resultados de investigación, los cuales se validan por medio de la ejecución y transformación en obra construida del proceso investigativo. También se contempla la publicación de investigaciones relacionadas con la pedagogía y didáctica de la arquitectura, el urbanismo y el diseño.

TECNOLOGÍA, MEDIOAMBIENTE Y SOSTENIBILIDAD. En esta sección se presentan artículos acerca de sistemas estructurales, materiales y procesos constructivos, medioambiente y gestión, relacionados con los entornos social-cultural, ecológico y económico.

DESDE LA FACULTAD. En esta sección se publican artículos generados en la Facultad de Diseño, relacionados con las actividades de docencia, extensión, formación en investigación o internacionalización, las cuales son reflejo de la dinámica y de las actividades realizadas por docentes, estudiantes y egresados; esta sección no puede superar el $20 \%$ del contenido.

TExTos. En esta sección se publican reseñas, traducciones y memorias de eventos relacionados con las publicaciones en Arquitectura y Urbanismo.

\section{A FRECUENCIA DE PUBLICACIÓN}

Desde 1999 y hasta el 2015, la Revista de Arquitectura publicó un volumen al año, a partir del 2016 se publicarán dos números por año en periodo anticipado, enero-junio y julio-diciembre, pero también maneja la publicación anticipada en línea de los artículos aceptados (versión Post-print del autor).

La Revista de Arquitectura se divulga mediante versiones digitales (PDF, HTML, XML) e impresas con un tiraje de 700 ejemplares, los tiempos de producción de estas versiones dependerán de los cronogramas establecidos por la editorial.

Los tiempos de recepción-revisión-aceptación pueden tardar entre seis y doce meses dependiendo del flujo editorial de cada sección y del proceso de revisión y edición adelantado.

Con el usuario y contraseña asignados, los autores pueden ingresar a la plataforma de gestión editorial y verificar el estado de revisión, edición o publicación del artículo.

\section{A CANJE}

La Revista de Arquitectura está interesada en establecer canje con publicaciones académicas, profesionales o científicas del área de Arquitectura y Urbanismo, como medio de reconocimiento y discusión de la producción científica en el campo de acción de la publicación.

\section{Mecanismo}

Para establecer canje por favor descargar, diligenciar y enviar el formato: RevArq FP20 Canjes

http://publicaciones.ucatolica.edu.co/revista/ arquitectura/RevArq_FP20_Canje_V2.doc

Universidad Católica de Colombia (2016, enero-junio). Revista de Arquitectura, 18(1), $1-144$.

ISSN: 1657-0308 E-ISSN: 2357-626X

Especificaciones:

Formato: $34 \times 24 \mathrm{~cm}$

Papel: Mate $115 \mathrm{~g}$

Tintas: Negro y policromía

\section{A CONTACTO}

DIRECCIÓN POSTAL:

Avenida Caracas No. 46-72. Universidad Católica de

Colombia. Bogotá D.C.(Colombia)

Código postal: 111311

Facultad de Diseño, Centro de Investigaciones (CIFAR). Sede El Claustro. Bloque "L", 4 piso, Diag. 46를. No. 15b-10. Editor, Arq. César Andrés Eligio Triana

Teléfonos: +57 (1) 3277300 - 3277333

Ext. $3109 ; 3112$ o 5146

Fax: +57 (1) 2858895

CORREO ELECTRÓNICO:

revistadearquitectura@ucatolica.edu.co cifar@ucatolica.edu.co

PÁGINA WEB:

www.ucatolica.edu.co vínculo Revistas científicas http://publicaciones.ucatolica.edu.co/revistas-cientificas http://editorial.ucatolica.edu.co/ojsucatolica/revistas_ucatolica/index.php/RevArq 
UNIVERSIDAD CATÓLICA DE COLOMBIA

PRESIDENTE

Édgar Gómez Betancourt

VICEPRESIDENTE - RECTOR

Francisco José Gómez Ortiz

VICERRECTOR JURÍDICO Y DEL MEDIO

UNIVERSITARIO

Edwin de Jesús Horta Vásquez

VICERRECTOR ADMINISTRATIVO

Édgar Gómez Ortiz

DECANO ACADÉMICO

Elvers Medellín Lozano

DIRECTORA DE INVESTIGACIONES

Elisa Urbina Sánchez

DIRECTORA EDITORIAL

Stella Valbuena García

\section{FACULTAD DE DISEÑO}

DECANO

Werner Gómez Benítez

DIRECTOR DE DOCENCIA

Jorge Gutiérrez Martínez

DIRECTOR DE EXTENSIÓN

Adriana Pedraza Pacheco

DIRECTOR DE INVESTIGACIÓN

Hernando Verdugo Reyes

DIRECTOR DE GESTIÓN DE CALIDAD

Augusto Forero La Rotta

COMITÉ ASESOR EXTERNO

FACUlTAD DE DisEÑo

Alberto Miani Uribe

Giovanni Ferroni Del Valle

Samuel Ricardo Vélez

Lorenzo Castro

FACULTAD DE DISEÑO

REVISTA DE ACCESO ABIERTO,

ARBITRADA E INDEXADA

Publindex Categoría B. Índice Bibliográfico Nacional

IBN. Colombia.

Redalyc. Red de Revistas Científicas de América Latina

y el Caribe, España y Portugal. Sistema de Información

Científica. México.

Proquest. ProQuest Research LibraryProQuest

Research Library ProQuest Research Library. Estados

Unidos

Ebsco. EBSCOhost Research Databases. Estados

Unidos.

Latindex. Sistema Regional de Información en Línea

para Revistas Científicas de América Latina, el Caribe,

España y Portugal (Directorio y catálogo). México.

Clase. Base de datos bibliográfica de revistas de cien-

cias sociales y humanidades. Universidad Autónoma

México.

Dialnet. Fundación Dialnet - Biblioteca de la Universi-

dad de La Rioja. España.

Actualidad Iberoamericana. (Índice de Revistas) Centro de Información Tecnológica (CIT). Chile.

Arla. Asociación de revistas latinoamericanas de arquitectura.

EDITORIAL

Av. Caracas No 46-72, piso 5

Teléfono: 3277300 Ext. 5145

editorial@ucatolica.edu.co

www.ucatolica.edu.co

http://publicaciones.ucatolica.edu.co/

IMPRESIÓN:

ESCALA Taller Litográfico

Calle 30 № 17-52 - (057 I) 2320482

Abril de 2016

\section{REVISTA DE ARQUITECTURA}

DIRECTOR

Werner Gómez Benítez

EDITOR

César Andrés Eligio Triana

EDITOR DE SECCIÓN

Carolina Rodríguez Ahumada

CONSEJO EDITORIAL

Werner Gómez Benítez

Jorge Gutiérrez Martínez

César Andrés Eligio Triana

Hernando Verdugo Reyes

\section{EQUIPO EDITORIAL}

COORDINADORA EDITORIAL

María Paula Godoy Casasbuenas mpgodoy@ucatolica.edu.co

DiseÑo Y MONTAJE

Juanita Isaza

juanaisaza@gmail.com

TRADUCTORES

INGLÉS

Massayel Cuéllar Hernández

massacuellar@gmail.com

CORRECTORA DE ESTILO

María José Díaz Granados M.

mariajose_dgm@yahoo.com.co

PÁGINA WEB

Centro de investigaciones (CIFAR)

DISTRIBUCIÓN Y CANJES

Claudia Álvarez Duquino

calvarez@ucatolica.edu.co
COMITÉ EDITORIAL Y CIENTÍFICO Cultura Y ESPACIO URBANO

Carlos Mario Yory, PhD

Universidad Católica de Colombia. Bogotá, Colombia

Sonia Berjman, $\mathrm{PhD}$

ICOMOS-IFLA, Buenos Aires, Argentina

Juan Carlos Pérgolis, MSc Universidad Piloto de Colombia. Bogotá, Colombia

Beatriz García Moreno, PhD

Universidad Nacional de Colombia. Bogotá, Colombia

Javier Peinado Pontón, Msc

Pontificia Universidad Javeriana. Bogotá, Colombia

Proyecto arquitectónico y URBano

Jean-Philippe Garric, PhD, HDR

Université Paris I Panthéon-Sorbonne. Paris, Francia

Debora Domingo Calabuig, $\mathrm{PhD}$

Universidad Politécnica de Valencia, España

Hugo Mondragón López, PhD

Pontificia Universidad Católica de Chile. Santiago, Chile

Germán Darío Correal Pachón, MSc Universidad Católica de Colombia. Bogotá, Colombia

Juan Pablo Duque Cañas, PhD

Universidad Nacional de Colombia. Bogotá, Colombia

Jorge Grané del Castillo, MSc Universidad de Costa Rica. San José, Costa Rica

\section{TECNOLOGÍA, MEDIOAMBIENTE Y SOSTENIBILIDAD}

Mariano Vázquez Espí, PhD.

Universidad Politéencica de Madrid, España.

Luis Carlos Herrera Sosa, PhD

Universidad Autónoma de Ciudad Juárez, México

Claudio Varini, PhD

Universidad Católica de Colombia. Bogotá, Colombia

Luis Gabriel Gómez Azpeitia, PhD Universidad de Colima. Colima, México 


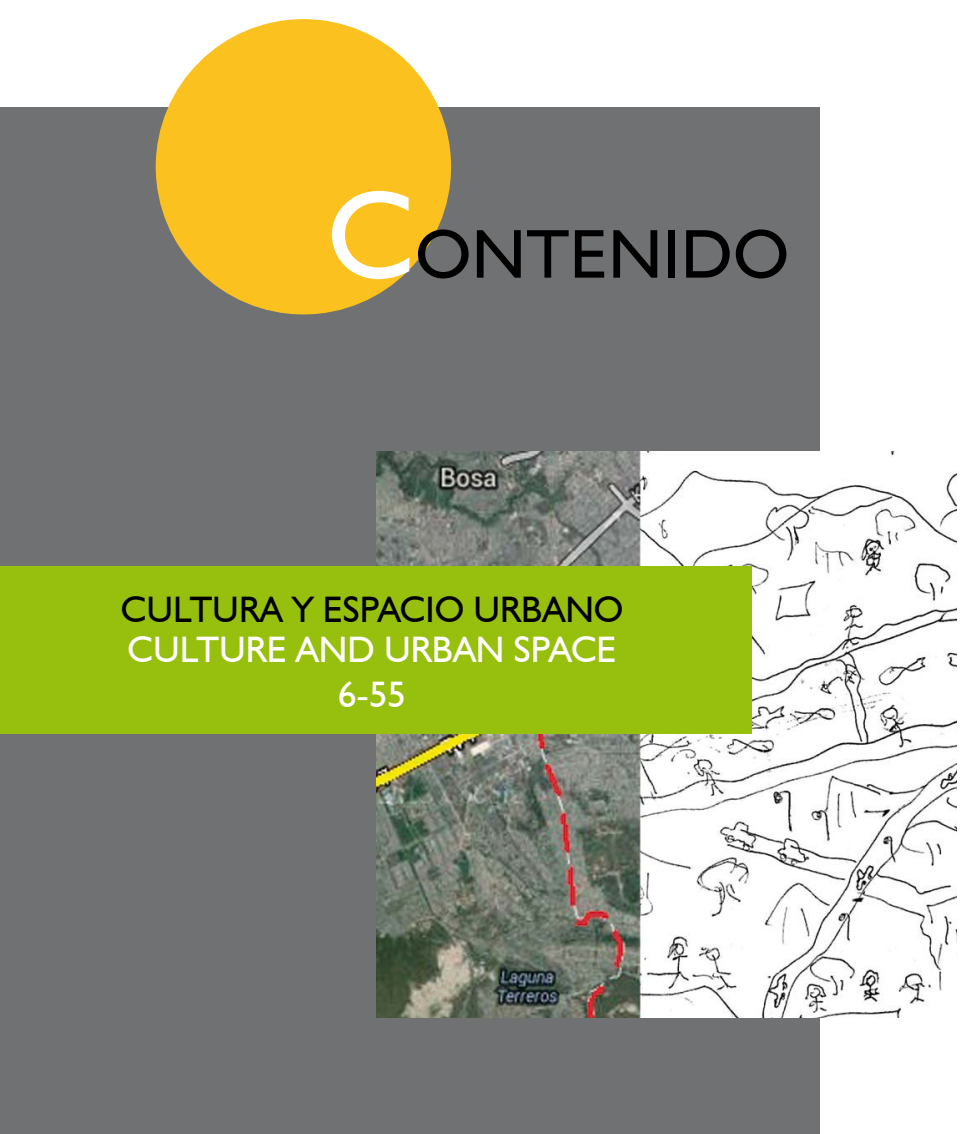

URBANISMO PARTICIPATIVO

CONSTRUCCIÓN SOCIAL DEL ESPACIO URBANO

MARY JOHANA HERNÁNDEZ ARAQUE

LA REPRESENTACIÓN SOCIAL DEL ESPACIO PÚBLICO PARA EL DISEÑO Y LA GESTIÓN DE TERRITORIOS SOSTENIBLES

UNA PROPUESTA TEÓRICO-PRÁCTICA Y METODOLÓGICA PARA UN URBANISMO PARTICIPATIVO

HeIDI NATALIE CONTRERAS-LOVICH

PROPUESTA DE UN SISTEMA DE INDICADORES PARA EVALUAR LA CALIDAD VISUAL DEL PAISAJE URBANO EN ASENTAMIENTOS INFORMALES

JOHANA ANDREA MESA CARRANZA, OSWALDO LÓPEZ BERNAL, ADRIANA PATRICIA LÓPEZ VALENCIA

\section{SEGREGACIÓN EN EL ESPACIO URBANO DE SOACHA}

¿TRANSMILENIO COMO HERRAMIENTA INTEGRADORA?

CARLOS AUGUSTO MORENO-LUNA

ARQUITETURA E INDUSTRIALIZAÇÃO DAS

CONSTRUÇÕES NA OBRA DE JOÃO FILGUEIRAS

LIMA - LELE

ELZA-LULI MIYASAKA, MARIELI LUKIANTCHUKI,

Michele C. B. Ferrari CaiXeta, Marcio-Minto Fabrício PÁg. 56

EL DISEÑO DE LA VIVIENDA DE INTERÉS SOCIAL

LA SATISFACCIÓN DE LAS NECESIDADES Y EXPECTATIVAS DEL USUARIO

ALEX LEANDRo PÉREZ-PÉREZ

\section{EXPLORACIONES MORFOLÓGICAS EN TEXTURAS} MODULARES

APROXIMACIONES DESDE EL OBIET TROUVÉ

AL DISEÑO PARAMÉTRICO

OMAR CAÑETE-ISLAS

TECNOLOGÍA, MEDIOAMBIENTE Y SOSTENIBILIDAD

TECHINOLOGY, ENVIRONMENT AND SUSTAINABILITY $76-125$
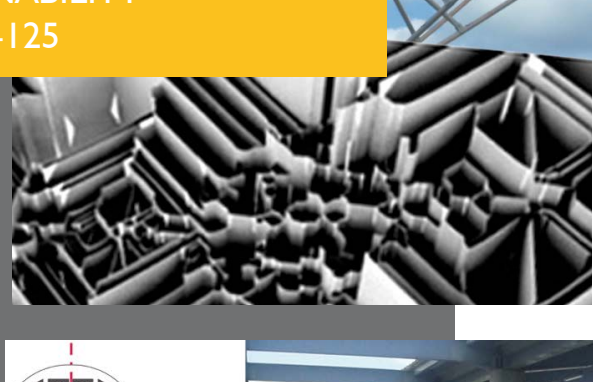

DESDE LA FACULTAD

FROM THE FACULTY 126-139

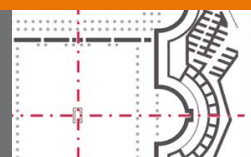

TEXTOS

TEXTS

I40-142
CONSTRUCCIÓN EXPERIMENTAL DE UN SISTEMA TRANSFORMABLE TENSADO PLEGABLE

CARLOS CÉSAR MORALES GUZMÁN

\section{LA SIMULACIÓN COMO HERRAMIENTA DE} DISEÑO Y EVALUACIÓN ARQUITECTÓNICA

PAUTAS RESUELTAS DESDE LA INGENIERÍA

JOHANNA TRUJILLO, ROLANDO ARTURO CUBILLOS-GONZÁLEZ

LAS RELACIONES ENTRE LA MOVILIDAD

Y EL ESPACIO PÚBLICO

TRANSMILENIO EN BOGOTÁ

Myriam STELLA Díaz-OSORIO, JuLIO CÉSAR MARRoQuíN

APRENDIZAJE, COMPOSICIÓN Y EMPLAZAMIENTO EN EL PROYECTO DE ARQUITECTURA [REVISIÓN DE LIBRO]

JUAN CARLOS PÉRGOLIS

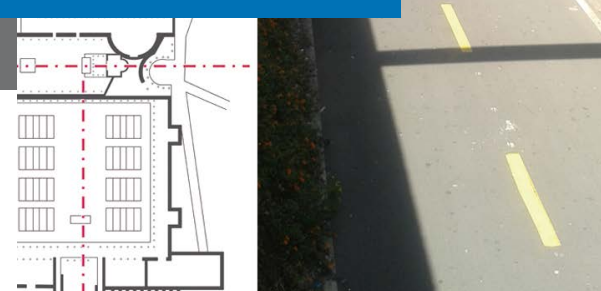




\title{
PROPUESTA DE UN SISTEMA DE INDICADORES PARA EVALUAR LA CALIDAD VISUAL DEL PAISAJE URBANO EN ASENTAMIENTOS INFORMALES
}

\author{
Johana Andrea Mesa Carranza, Oswaldo López Bernal \\ Universidad del Valle, Cali (Colombia) \\ Escuela de Arquitectura. Grupo Hábitat y Desarrollo Sostenible
}

Adriana Patricia López Valencia

Universidad del Valle, Cali (Colombia)

Escuela de Ingeniería de los Recursos Naturales y el Ambiente (Eidenar), área de gestión ambiental

\section{Mesa Carranza, J. A., López Bernal, 0. \& López Valencia A. P. (2016) Propuesta de un sistema de indicadores para evaluar la calidad visual del paisa- je urbano en asentamientos informales. Revista de Arqui- tectura, I8(I), 35-47. doi: 10.14718/RevArq.2016.18.1.}

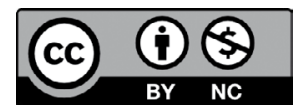

http://dx.doi.org/10.14718/RevArq.2016.18.1.4
Johana Andrea Mesa Carranza

Arquitecta, Universidad del Valle, Cali (Colombia).

Joven investigadora e innovadora "Virginia Gutiérrez de Pineda" de Colciencias 2012.

Ganadora del primer premio de vivienda económica, ConvivE IV, concurso binacional de hábitat andino de la revista Escala, 2009.

Investigadora, Escuela de Arquitectura de la Universidad del Valle. johanandrea89@gmail.com

\section{Oswaldo López Bernal}

Arquitecto, Universidad Católica de Colombia, Bogotá (Colombia). Magíster en Gestión ambiental urbana, Universidad Javeriana, Bogotá (Colombia)

$\mathrm{PhD}$ en Urbanismo, Universidad Nacional Autónoma de México.

Estancia posdoctoral en la Universidad de Montreal, programa de Faculty Research Program del Gobierno Canadiense.

Profesor e investigador, Escuela de Arquitectura, Universidad del Valle. oswaldo.lopez@correounivalle.edu.co

\section{Adriana Patricia López Valencia}

Arquitecta, Universidad del Valle.

Especialista en Gestión ambiental, Universidad Autónoma de Occidente.

Magíster en Urbanismo, Universidad Nacional de Colombia.

$\mathrm{PhD}$ en Ciencias Ambientales, Universidad del Valle.

Ganadora del premio Green Talents 2010 del Ministerio de Educación e Investigación de Alemania.

Profesora e investigadora, Escuela de Ingeniería de los Recursos Naturales y el Ambiente, Universidad del Valle.

adriana.lopez@correounivalle.edu.co

\section{RESUMEN}

Los asentamientos informales son producto de procesos espontáneos de urbanización y se conforman sin ninguna planificación oficial, generando exclusión social y marginalidad, las cuales repercuten negativamente en el aspecto físico del entorno urbano y en la calidad de vida de los habitantes. Este texto se enfoca en la construcción de los lineamientos de confort ambiental orientados a la calidad visual del paisaje urbano; a partir de una revisión bibliográfica descriptiva se presentan los diferentes autores y conceptos que definen al paisaje urbano; se identifican los principales componentes que lo conforman $y$, a partir de estos, se propone un sistema de indicadores para valorar su calidad visual, bajo la integración de factores inherentes a las dimensiones ecológica, estética y cultural, los cuales contribuyen a definir el diagnóstico de cada componente propuesto, además de establecer un sistema de evaluación que favorezca el mejoramiento de la calidad visual del paisaje urbano informal, proporcionando resultados que ayuden al proceso de diseño y a la preservación o el mejoramiento del mismo. PALABRAS CLAVE: diseño del paisaje, diseño urbano, paisaje cultural, paisaje natural, protección del paisaje.

PROPOSAL FOR A SYSTEM OF INDICATORS TO ASSESS THE VISUAL QUALITY OF THE URBAN LANDSCAPE IN INFORMAL SETTLEMENTS

\begin{abstract}
Informal settlements are the result of spontaneous processes of urbanization and are formed without any official planning, generating social exclusion and marginalization, which adversely affect the physical appearance of the urban environment and quality of life of the inhabitants. This text focuses on building environmental guidelines comfort-oriented visual quality of the urban landscape; from a descriptive literature review, there is a presentation of different authors and concepts that define the urban landscape; the main components that comprise it are identified and, from these, an indicator system is proposed to assess their visual quality, low integration inherent ecological, aesthetic and cultural dimensions factors, which help define the diagnosis of each proposed addition to establish an evaluation system that favors improving the visual quality of informal urban landscape, providing results that help the design process and the preservation or improvement of the same component.

KEYWORDS: Landscape design, urban design, cultural landscape, natural landscape, landscape protection.
\end{abstract}

\section{INTRODUCCIÓN}

Este texto se presenta como parte de la investigación "Mejoramiento del confort ambiental urbano en asentamientos informales", realizada en el marco del programa Jóvenes investigadores e innovadores "Virginia Gutiérrez de Pineda", Convocatoria 566 del 2012 de Colciencias, iniciada en febrero del 2013 y finalizada en febrero del 2014, a través del proyecto académico-investigativo adelantado por el grupo de investigación "Hábitat y desarrollo sostenible" de la Escuela de Arquitectura, con el apoyo del área de Gestión Ambiental de Eidenar, Universidad del Valle, a partir de la idea de formular un sistema de medición ambiental urbano enfocado principalmente en la calidad del paisaje urbano que, aplicado a asentamientos informales, contribuya al mejoramiento de las condiciones de la calidad físicoespacial del espacio público, e incremente la calidad de vida de la población socialmente más vulnerable en las ciudades colombianas.

En primera instancia, se resalta que la intención de evaluar la calidad visual del paisaje urbano es estudiada desde hace algunos años por varios autores (Lynch, 1992; Fry, Tveit, Ode y Velarde, 2009; Briceño, Contreras y Owen de Contreras, 2012), los cuales buscan incorporar e integrar la dimensión ecológica, estética y cultural en la construcción del paisaje urbano, como herramienta que contribuya a mejorar la calidad de vida ambiental de las ciudades, como objetivo específico dirigido a la construcción del paisaje urbano sostenible.

El artículo está estructurado en dos partes. En la primera se expone una visión general de las formas en las que puede ser evaluado un paisaje, abordada por diferentes autores con sus definiciones generales y específicas respecto al tema; en la segunda se presentan los resultados de los indicadores propuestos que sintetizan el valor ecológico, estético y cultural del paisaje urbano alimentando el concepto de calidad del paisaje, tomando en cuenta lo descrito a lo largo del texto.

Como punto de partida es importante entender que los asentamientos informales son, por lo general, áreas de gran extensión de territorio que albergan comunidades en viviendas 


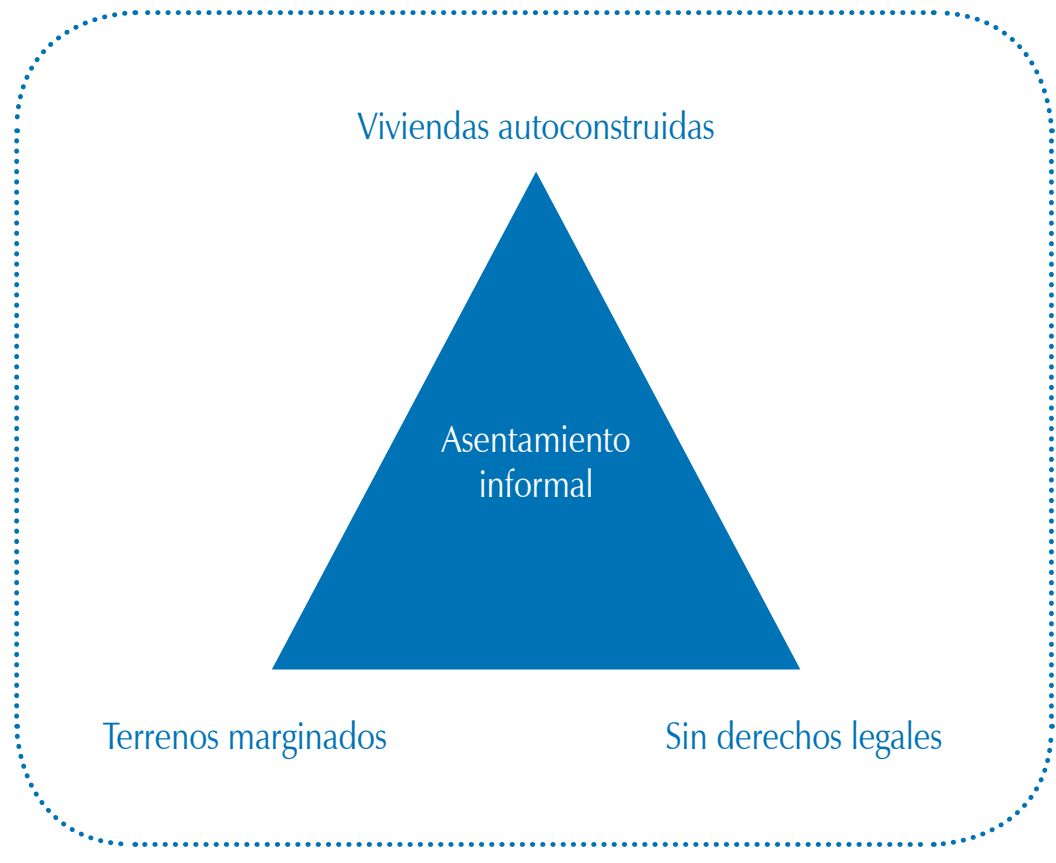

(1) Figura 1. Características de un asentamiento informal

Fuente: elaboración propia. autoconstruidas, bajo deficientes condiciones de vida y sin ninguna iniciativa de planificación oficial (Arango, 1990; Busquets, 1999; Saldarriaga, 2002; Duhau, 2003; Torres, 2007) (figura 1).

Normalmente ubicados en los bordes de las ciudades, en terrenos marginados o en zonas vulnerables, los asentamientos informales son el producto de una necesidad inmediata de obtención de vivienda de las comunidades urbanas de escasos recursos (Rebotier, 2010), problema que surge debido a la pérdida de control por parte del Estado sobre las áreas de expansión urbana, y a las deficientes propuestas de política de vivienda de interés social (VIS) (Brakarz, Greene y Rojas, 2002; Saule, 2008) que da como resultado la proliferación de viviendas elaboradas con materiales reciclados o provisionales, que se construyen con un saber empírico, ajeno al orden urbano formal (Clichevsky, 2000; Duhau, 2003; Hernández, 2007) en áreas de preservación ambiental o en zonas de alto riesgo con altas pendientes (Davis, 2006; Rozo, 2011).

La figura 1 resume los principales aspectos hasta aquí expuestos y muestra cómo la pobreza y la desigualdad ocasionan una baja en los niveles de habitabilidad de los barrios informales, poniendo en riesgo, por el aumento de los mismos, la calidad de los espacios públicos y de las zonas verdes de la ciudad, ya que el acelerado crecimiento de las ciudades y la falta de planificación y control adecuado han conducido a la insuficiente generación de espacio público (Hernández, 2008; Duhau, 2003) debido a la ocupación total de los terrenos por parte de la población más pobre, dejando solo los espacios de circulación, lo que aumenta la inequidad en estas zonas e invade el equilibrio ambiental del sistema urbano (Sáez, García y Roch, 2010; Rozo, 2011).
Estas áreas urbanas suelen desarrollarse en entornos caracterizados por la segregación y la marginalidad, que los desconecta de las principales actividades de la ciudad, lo que evidencia el nivel de pobreza urbana en la que habitan estas poblaciones, la magnitud de las carencias y la profundidad de sus consecuencias sobre el desarrollo humano.

Bajo estas premisas, este artículo tiene como objetivo proponer un sistema de indicadores que contribuya a evaluar la calidad visual del paisaje urbano en áreas urbanas informales, que aporte al mejoramiento de las condiciones físico-espaciales del espacio público y al enriquecimiento del sentido de pertenencia de la población más pobre, a partir de la transformación del entorno construido, tomando como punto de partida el concepto de calidad visual urbana, el cual se analiza a lo largo del texto, para llegar finalmente a los primeros resultados de la propuesta de un modelo de indicadores aplicable a un asentamiento informal.

\section{Metodología}

El desarrollo metodológico de la investigación aborda, en una primera fase, la revisión bibliográfica de carácter descriptivo de diferentes conceptos y definiciones de la idea de paisaje urbano, identifica algunas aproximaciones metodológicas y los criterios que definen la calidad de dicho paisaje. Dentro de los aspectos consultados se identificaron tres dimensiones, la primera se refiere al ámbito ecológico y territorial, la segunda a la dimensión estética y visual orientada hacia la capacidad de percepción del observador y, por último, la cultura del paisaje. A partir de esta revisión se da forma a la propuesta de un sistema de medición basado en tres grandes grupos de atributos: los ecológicos, los estéticos y los culturales, a estos se les determinaron componentes, indicadores y variables, de esta manera se liga tanto el marco conceptual como la metodología para la comprensión integral del sistema de medición, con miras a la posibilidad de ser implementado en un asentamiento informal.

\section{RESULTADOS}

\section{EL PAISAJE: CONCEPTO Y CAMPOS DE ESTUDIO}

Partiendo de que el paisaje no es reflejo de una única corriente o de una sola disciplina académica, sino, por el contrario, es un concepto que tiene numerosos puntos de vista y significados que lo definen, es importante aclarar cuál es 
la descripción que aplica para el objeto de estudio de esta investigación, ya que el concepto no se toma de una sola definición, sino que se construye con base en diferentes aproximaciones que ayudan a definir la noción de paisaje.

Diversos autores hacen énfasis en determinados elementos a la hora de definir el paisaje, lo que da lugar a comprenderlo como la lectura del territorio a través de los recursos perceptivos del individuo, que integran las dimensiones naturales y artificiales del territorio, como resultado de la interacción inmaterial de la cultura y las costumbres de las poblaciones que habitan dicho territorio (DRAE, 2001; Villarino, 1985, p. 485; Santos, 2000; Arias, 2003, p. 89; Ojeda, 2011; Bertand, 1968; Zonneveld, 1984 y Etter, 1990, citados por Morlans, 2005; Pérez, 2000).

De esta forma, el paisaje urbano es el resultado de la acción combinada de factores humanos, fenómenos físicos y factores naturales, que modifican permanentemente el espacio a través de la historia, por diversos procesos a lo largo del tiempo, dejando una huella visible en el desarrollo de las ciudades (Briceño, Contreras y Owen, 2012).

En este sentido, es posible afirmar que el paisaje puede ser abordado a partir de tres dimensiones: la ecológica, la estética y la cultural (Jordana, 1992, citado por: Dos Santos, 2011; Briceño et al., 2012; Seia, 2004, citado por Arias, 2013).

La primera dimensión se hace desde los ámbitos ecológico y territorial, que estudian el efecto de la configuración espacial o "estructura morfológica" (Vila, Vargas y Ribas, 2006, p. 155) de los mosaicos terrestres sobre una amplia variedad de fenómenos ecológicos y sociales, a múltiples escalas espaciales y temporales (Forman, 2004; Muñoz, 2004; Rodríguez, 2003; Moreno, 2007; Matteucci, 2009). Esta dimensión está estrechamente vinculada al uso y consumo de los recursos naturales de las zonas urbanas, y es catalogada como un entorno natural que el hombre, con sus actividades y tradiciones, transforma en un paisaje culturalmente aprovechado (Troll, 1938, citado por Morlans, 2005; Steiner, 2008), con el propósito de buscar equidad social y equilibrio ecológico sobre la calidad ambiental y de vida, contribuyendo a la idea de sostenibilidad (Briceño, 2009).

La segunda dimensión es la estética y visual, que se orienta hacia la capacidad de percepción del observador (Pérez, 2000; Muñoz, 2004; Masmela, 2010). Se refiere a la porción de terri- torio que es posible abarcar con los dispositivos perceptivos (Lynch, 1992; Santos, 2000) apreciables por el observador cuando se sitúa en un punto del mismo o se mueve por él (Villarino, 1985 , p. 482) para crear una imagen mental del espacio a través de la experiencia vivida con el entorno (Ojeda, 2011).

Mediante la percepción, el paisaje pasa a ser una realidad física experimentada por el hombre (Villarino, 1985), donde cada grupo humano crea una percepción propia del espacio que ocupa, ya que de una forma u otra le pertenece a él o a sus antepasados (Escribano et al., 1989, p. 46). Este enfoque está conectado con la relación afectiva y valorativa que tiene un espacio para los usuarios (Briceño, 2002) y busca asegurar la identidad y estructura formal del mismo, de acuerdo con las necesidades y preferencias de la población.

Por último, el análisis se aborda desde la dimensión cultural del paisaje, la cual se centra en el aspecto social de las comunidades, como expresión estética de las formas de vida de la sociedad (Ojeda, 2011; Briceño et al., 2012). Es el resultado de los efectos de las actividades humanas en un territorio que es transformado a través de las costumbres y necesidades de una población determinada (Berque, 2006; Gómez, 2010). En la Convención del Patrimonio Mundial de la Unesco, el paisaje se define como la repuesta a las formas de vida, tradiciones y creencias de una población (Unesco, 1972) y se refleja en la manera de construir sus viviendas y de ocupar el territorio (UN-Habitat/Rolac, 2004), concibiendo al paisaje cultural como un espacio natural modificado para sobrevivir, como una realidad compleja, integrada por componentes naturales y culturales, tangibles e intangibles (Martorell, 2003), buscando establecer un modelo urbano que establezca la relación de los ecosistemas con los componentes físicos de cada cultura urbana, para así preservar los espacios más relevantes a la hora de una intervención.

En concordancia con lo anterior, y citando a Navarro, "el paisaje existe en tanto un individuo lo mire y lo interprete, pero si no existiesen los elementos de la naturaleza no habría nada qué interpretar y si solo está la naturaleza y no está el individuo para interpretarla tampoco habría paisaje" (2003, p. 9). Así, al plantear la importancia de cada uno de los componentes a la hora de hablar de paisaje, la ausencia de algunos de ellos daría como resultado un análisis incompleto de las determinaciones culturales, sociales e históricas que enmarcan a dicho territorio. 
Por otro lado, Navarro (2003) estudia el concepto de otro autor que clasifica el paisaje a partir de tres relaciones: "paisaje como naturaleza disponible para el hombre; paisaje como producto social y paisaje como construcción simbólica (Peña, 1998)"; lo anterior ayuda a definir los lineamientos en cuanto a los tipos de análisis y categorías por las cuales se puede estudiar un paisaje urbano, refutando la idea de que para el análisis integral de la calidad del paisaje se deben tener en cuenta todas las variables a la hora de generar una propuesta de mejoramiento.

Estas tres dimensiones conceptuales que se estudian en el texto: la estética, la ecológica y la cultural, forman en sí un sistema de definiciones compuesto por la suma de significados asociados unos con otros (Tesser, 2000), y se concluye que un paisaje se integra a partir de varios componentes: "el paisaje natural como el medio, el ser humano como organismo y el paisaje cultural como resultado" (Gómez, 2010, p. 96) que, combinados, contribuyen al análisis integral del paisaje a partir de su descripción, interpretación y valoración, lo cual nos permite llegar a una aproximación del modelo de indicadores que contribuyan a alimentar la idea de calidad visual del paisaje en asentamientos informales.

\section{INDICADORES PARA EVALUAR LA CALIDAD VISUAL DEL PAISAJE URBANO}

A partir de la identificación de los diferentes tipos de estudios del paisaje se proponen una serie de variables e indicadores que buscan evaluar el estado de la calidad visual del paisaje urbano por medio de los valores culturales de los asentamientos informales, relacionados con el estudio morfológico y perceptual del paisaje, lo que finalmente llevaría al mejoramiento de la calidad en los espacios donde logre implementarse dicho modelo de intervención (Escribano et al., 1991, citado por Tesser, 2000; Fry et al., 2009; Briceño et al., 2012).

\section{Atributos ecológicos}

Este atributo tiene como objetivo la búsqueda de la equidad social y el equilibrio ecológico en los asentamientos urbanos, estudia los paisajes tanto naturales como antrópicos, además de las dinámicas espaciales del territorio (Muñoz, 2004; Rodríguez, 2003; Villa, Vargas y Ribas, 2006, p. 155; Moreno, 2007). Está directamente asociado al uso y consumo de los recursos naturales en las zonas urbanas (Briceño, 2009) y se centra en el conocimiento y la comprensión del desarrollo natural de la ciudad, así como en la adaptación a la actividad humana, reflejada en sus espacios y construcciones individuales o grupales.

Su valoración es objetiva ya que está relacionada con la identificación del estado de los ecosistemas y el ambiente construido, manifestado visualmente a través de la disposición de la forma, las funciones, los elementos y las dinámicas de la estructura urbana (Santos, 2003, p. 44), analizando sus interacciones e impactos de acuerdo con la dinámica de la población, con el propósito de ubicar usos específicos que puedan resultar mejor adaptados a la hora de un mejoramiento (McHarg, 2000).

Con esa finalidad, este atributo analiza cómo se ve, se organiza y se configura la forma urbana; estudia cómo las actividades humanas generan impactos en el espacio y modifican el paisaje debido a la relación directa entre los objetos creados por el hombre y la naturaleza, como respuesta a las necesidades de un grupo social (Fighera, 2005, p. 115; Díaz Pineda y Schmtz, 2003, citados por Gurrutxaga y Lozano, 2008), las cuales pueden generar dinámicas acertadas $\mathrm{O}$ impactos negativos en el territorio.

En este sentido, cuando se habla de objeto se hace referencia a la forma, a la apariencia de las cosas o a la adecuación de la materia, buscando contribuir a un objetivo o necesidad (Fighera, 2005); debido a esto, el atributo se analizará por medio de la relación paisaje-objeto, ya que el paisaje urbano es el conjunto de formas y objetos que las comunidades van creando como respuesta a las necesidades y adaptación al medio natural.

Esta relación paisaje-objeto busca analizar de manera lógica la forma urbana como respuesta a sus componentes e interrelaciones presentes en las comunidades (Pérez, 2000; Briceño et al., 2012), lo cual ayudaría a definir áreas para un uso potencial en donde coincidan la mayoría de elementos considerados favorables, en ausencia de mayores condiciones de deterioro, buscando entender el objeto como la forma que encierra el pasado y el presente de las comunidades, ya que conjunto de sistemas de objetos y de acciones (Santos, 2000) que en un momento dado expresan las sucesivas relaciones que se han dado y se dan entre el hombre y la naturaleza (Fighera, 2005; Gurrutxaga y Lozano, 2008, p. 522).

En este sentido, este atributo se analiza a través de cuatro componentes: el primero corresponde al grado de conservación urbana, que indica la 


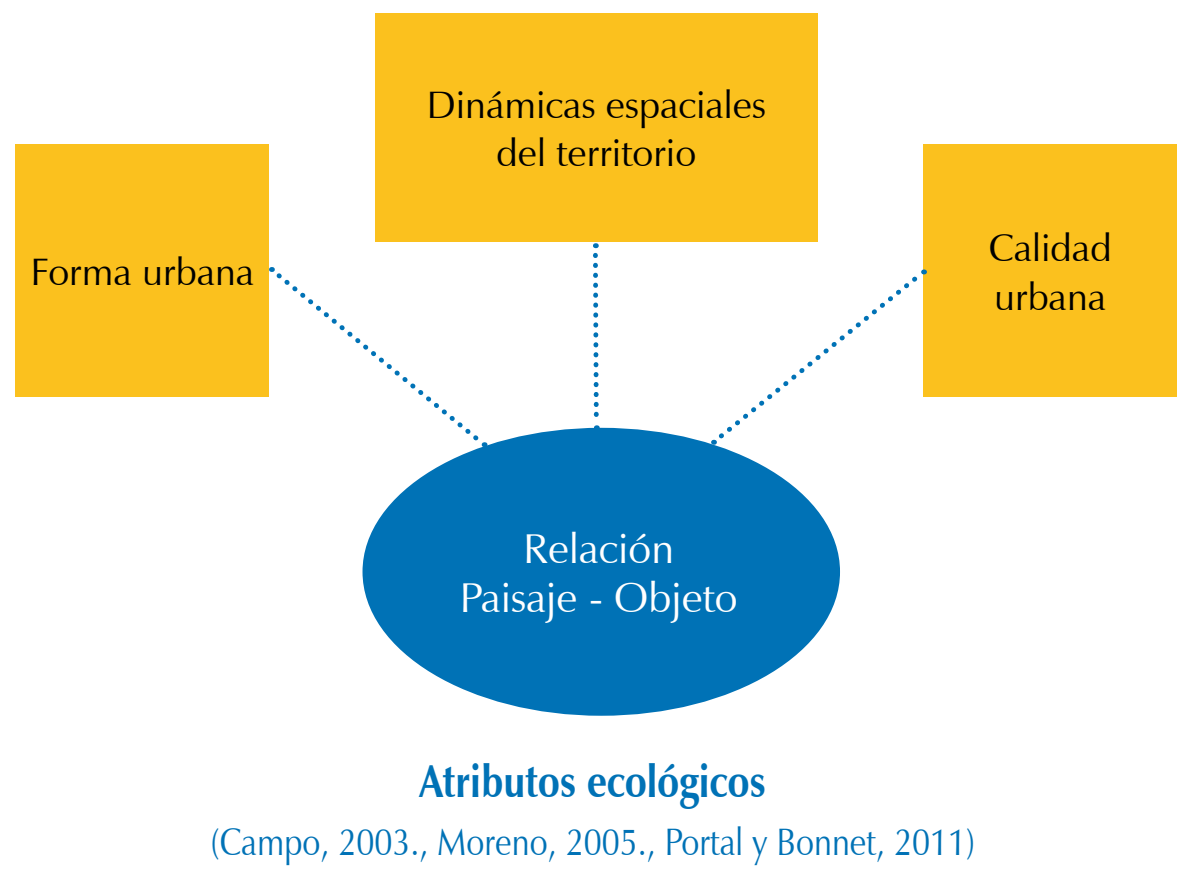

baja, media o alta preservación y estado de los elementos construidos (Fry et al., 2009; Briceño et al., 2012), estudiada a través de cuatro indicadores y trece variables (tabla 1); el segundo componente es el grado de conservación natural, que indica el estado de los elementos naturales, según la poca, media o alta intervención humana, debido a "que el medio natural condiciona a los sistemas sociales, a través de los recursos que potencialmente pueden proporcionar, y a su vez, los sistemas sociales intervienen sobre los naturales a través de la cultura" (Curtis y Massarini, 2007), analizada a través de dos indicadores y siete variables (tabla 1).

El tercer componente es la forma urbana, que identifica el tipo de morfología urbana, estudiando la trama, manzana, calle, cruce y espacios abiertos (Salas, 1999; Pérgolis, 2002; Acuña, 2005; Briceño y Gil, 2005), por medio de cinco indicadores y quince variables (tabla 1) que analizan la ubicación de los elementos arquitectónicos y urbanos que ayudan a generar las imágenes de las cuales se alimenta la percepción visual.

El último y cuarto componente son las actividades, las cuales indican los diversos usos de la zona de estudio, caracterizados por su funcionalidad y zonificación (Lombo, 1998), reconociendo la proximidad de la población a los servicios básicos de la zona, y el nivel de accesibilidad y cercanía que hay entre las viviendas y los equipamientos, examinándolos a través de dos indicadores y cinco variables (tabla 1) que contribuyen a entender cuál es la dinámica urbana del área por estudiar, para tener una visión concreta del uso que se le está dando a un espacio para definir si este es conflictivo o no.
En la figura 2 se resumen los principales aspectos por estudiar en este atributo y se muestra la relación paisaje-objeto como el elemento central sobre el cual se deben enfocar el resto de los análisis.

\section{Atributos estéticos}

Para los atributos estéticos el objetivo es el mejoramiento de la identidad y estructura formal de un espacio de acuerdo con las necesidades y preferencias de la población, caracterizadas por las apreciaciones subjetivas del entorno (Lynch, 1992; Santos, 2000), y apunta directamente a entender el paisaje como una creación propia de la experiencia humana (Khzam, 2008) a través de una experiencia sensorial (percepción) que genera un efecto de placer o un sentimiento de aprecio (utilidad) (Briceño et al., 2012), que no solamente está ligado a los recursos tangibles o a los bienes materiales, sino a los deseos, las percepciones y los imaginarios que tiene una población acerca de su entorno (Niño, 2006, p. 33), adquiriendo un valor para la vida cotidiana de las poblaciones, convirtiéndose en un lugar personalizado, único y posiblemente irrepetible (Arias, 2001).

La estética es la rama de la filosofía relacionada con la percepción de la belleza y la fealdad, esta se ocupa también de comprender si estas cualidades están de manera objetiva presentes en las cosas, a las que pueden calificar, o si existen solo en la mente del individuo; por tanto, su finalidad es mostrar si los objetos son percibidos de un modo particular o si los objetos tienen, en sí mismos, cualidades específicas o estéticas diferenciándolas entre lo bello, lo agradable o lo feo (Acuña, 2005, p. 19).
A Figura 2. Áreas temáticas de estudio de los atributos ecológicos

Fuente: elaboración propia. 


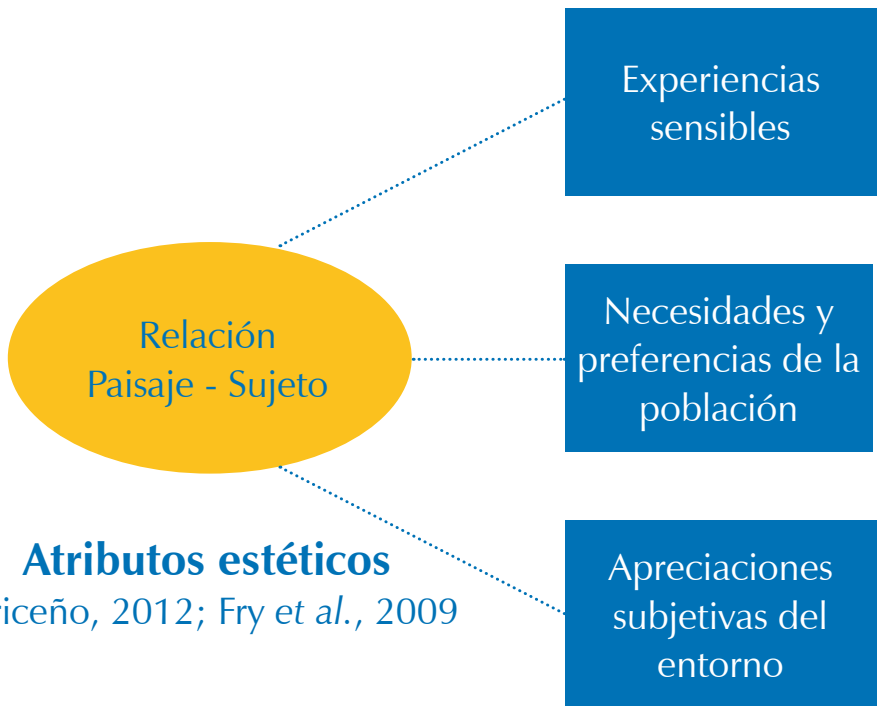

(A) Figura 3. Áreas temáticas de estudio del atributo estético

Fuente: elaboración propia.
En este sentido, la estética del paisaje pretende realizar un rastreo de los factores que modelan la identidad urbana, con el fin de generar una base conceptual que permita vincular las valoraciones estéticas con la identidad de la ciudad y las manifestaciones visuales en ellas encontradas, no solo a través de los valores compositivos, sino a partir de cómo el hombre vive en el paisaje de su ciudad, ya que sus sentimientos, aceptación o rechazo de situaciones o percepciones, influyen en sus respuestas y su comportamiento frente al paisaje (Jacobs, 1973, citado por Arias, 2001, p. 180).

Entonces, el paisaje en este atributo corresponde a la imagen sensorial captada por un observador, por medio de una apreciación subjetiva ligada a la identidad y cultura del espectador (Escribano et al., 1989, p. 46), que guarda una estrecha relación con los valores, las actitudes y las preferencias de una población frente a un espacio (Sánchez, 2003). Debido a que los criterios de los campesinos no son los mismos que los de un urbanista, sus paisajes ideales son distintos, porque las directrices rurales son de tipo adaptativo (Santos, 2003, p. 46) y son resultado de un ajuste ecológico-cultural, donde la relación del hombre con el medio es más profunda (Pérez, 2000; Muñoz, 2004; Masmela, 2010).

En este sentido, el paisaje como percepción tiene su centro de interés y de valoración en componentes de distinta naturaleza según se refiera a ámbitos naturales o a otros formalmente elaborados por la acción del hombre, por su belleza y armonía, e incluso por su dramatismo y conflictividad.

Es por eso que a través de la percepción se pueden construir múltiples lecturas de la ciudad, darles significados diferentes y catalogarlos como espacios de referencia, como zonas peligrosas (Niño, 2006, p. 131), analizando este atributo con la interacción: paisaje-sujeto.

Esta relación paisaje-sujeto busca estudiar los elementos urbanos importantes de las intervenciones humanas por medio de la valoración hecha por la persona que percibe el paisaje (Boira, 1987; Caquimbo, 2010; Ojeda, 2011). El estudio se centra en la forma de percibir un espacio urbano y catalogarlo de bello, al tiempo que se identifiquen las estructuras significativas que hacen que un lugar adquiera pertenencia y utilidad (Briceño et al., 2012).

Para Lynch, el paisaje es algo que no solo ha de verse, sino, más aún, debe recordarse. Ya que todo hombre establece vínculos y recuerdos con el paisaje que son determinantes para su equilibrio vital y emocional, ya sean individuales o colectivos; es por eso que el análisis se enfoca en dos indicadores: el primero será el grado de belleza, que indica el grado de aceptación y agrado de elementos o conjuntos que, sin ser necesarios, contribuyen a la tranquilidad y al sentido estético del paisaje urbano (Briceño et al., 2012; Liernur, 2004; Morgan, 2006, p. 42); pueden ser elementos construidos o naturales, que son gratificantes para la población por el simple hecho de observar, catalogando la belleza no como una cualidad de un objeto independiente, sino por el contrario, como un valor que el observador adjudica a un objeto o espacio (Segovia y Oviedo, 2000; Meda, 2011, p. 2) y se identifica a través de un indicador y seis variables (tabla 1) que determinen los elementos claves de referencia visual, tanto naturales como urbanos en los asentamientos por estudiar.

Por otro lado está el grado de utilidad, que indica los objetos o espacios que satisfacen necesidades específicas, por lo cual las personas los aprecian y valoran positivamente (Briceño et al., 2012, p. 42); pueden ser lugares de distracción, recreación, juego o de interacción social (Sánchez, 2003; Martignoni, 2009) y se identifican a través de variables que reconozcan los elementos o espacios de contacto e interacción natural o urbana que tiene la población con su entorno (Caquimbo, 2010) analizado por medio de dos indicadores y ocho variables (tabla 1).

En la figura 3 se muestran los principales aspectos por analizar en el atributo estético, teniendo como punto de partida la relación paisaje-sujeto. 


\section{Atributos culturales}

Para la valoración del componente cultural se debe tener en cuenta que este tiene como objetivo constituir un modelo urbano que establezca la relación de los ecosistemas con los componentes físicos de cada cultura urbana.

Este componente es catalogado como el resultado de la acción de un grupo social a través del dinamismo cultural de varias generaciones sobre un paisaje natural (Aponte, 2003; Sabaté, 2004, p. 42; Santos, 2003, p. 44; Garre, 2001), es decir, es el registro humano sobre el territorio (Gómez, 2010) que se caracteriza por la singularidad de sus emplazamientos, la forma de sus entramados y la personalidad de sus construcciones; en definitiva, por la suma de elementos patrimoniales que reflejan sociedades y modos de producción que se han mantenido a lo largo de los años (Santacana y Serrat, 2009, citados por Zárate, 2010, p. 189), permitiendo la lectura del pasado, así como el reconocimiento y funcionamiento de sus formas de vida, creencias, representaciones, conocimientos, hábitos y prácticas, que los habitantes han construido a lo largo de la historia, confiriéndoles un valor especial frente a otros paisajes y justificando los esfuerzos de la sociedad para construirlos y, en buena medida, recuperarlos (Zarate, 2010), cargados de un alto potencial de significados y simbolismos que terminan siendo la materialización de la interacción subjetiva entre cultura, naturaleza y sociedad (Rojas, 2007).

La cultura fue el objetivo esencial de los enfoques regionales $y$, sobre todo, de un amplio movimiento conocido con el nombre alemán de landschaft, que identificaba cuatro fuerzas modeladoras del paisaje cultural: espacio, hombre, cultura e historia, centrando el origen en el orden y la evolución de las formas esenciales del paisaje cultural (Santos, 2003).

En este sentido, la cultura conecta de distintas maneras lo económico, lo ambiental y lo social, mediante el comportamiento humano, sus necesidades y preferencias; debido a esto, el paisaje cultural hace referencia a la forma de vida más o menos organizada que caracteriza a una cultura como respuesta a una manera de subsistir y progresar de algunos asentamientos.

Atendiendo a estas consideraciones se encuentran dos maneras de analizar el paisaje cultural, una es por medio de la elaboración de los mapas culturales, los cuales buscan codificar y localizar sobre un plano cartográfico la distribución espacial de la vida cotidiana de estas poblaciones a través de códigos, símbolos e imaginarios, explicando el significado y determinando la prioridad que para los grupos y sectores sociales tiene cada uno de los elementos identificados (Chaparro, 2004, p. 18).

La otra es a través de la perspectiva del espacio vivido (Viqueira, 1994; Lerma, 2013), el cual se centra en la relación directa entre las personas y su espacio próximo, dándole prioridad a la manera como la gente reconoce y significa el espacio, ya que este representa sus intereses y deseos, estudiando cómo se sienten, nombran y apropian del lugar, en el transcurso de su vida cotidiana.

Entonces, al entender que las formas del paisaje cultural son en buena medida respuesta a las necesidades de la población, estas se analizan por medio de la relación paisaje-cultura que busca estudiar la forma urbana como resultado de fuerzas sociales que han transformado el territorio a lo largo del tiempo.

Esta relación paisaje-cultura busca el reconocimiento morfológico de un lugar como un rasgo cultural (Aponte, 2003; Ojeda, 2011), abarcando el tema de la distribución del territorio a partir de las tradiciones y los modos de vida de la población (Berque, 2006; Gómez, 2010), asignándole mayor valor a ciertos espacios que por generaciones han sido importantes para el desarrollo de una comunidad, con la idea de preservarlos a la hora de hacer una nueva intervención (Garre, 2001).

Este atributo se evalúa por medio del componente denominado Tipología de espacios de interés cultural (Garre, 2001), el cual contribuirá a identificar los lugares simbólicos exteriores de las comunidades por medio de la identificación de los espacios públicos más importantes en el desarrollo de la vida cotidiana de los pobladores (Perahia, 2007), y de cómo la importancia que tienen estos ayuda a definir la morfología de su ocupación; todo esto, centrándose en el valor simbólico que las personas otorgan al lugar que habitan y al significado que tiene para ellos en el mapa mental que usan para desenvolverse en el espacio donde desarrollan su vida diaria (Álvarez, 2011).

Este enfoque es representado por un indicador y siete variables (tabla 1) que determinan los lugares más importantes y representativos del asentamiento por analizar, los cuales servirán de herramienta para la planificación y el ordenamiento del territorio, así como para la creación, construcción, mejoramiento y conservación de la ciudad, entendida como un conjunto articulado 
$\rightarrow$ Figura 4. Áreas temáticas de estudio del atributo cultural Fuente: elaboración propia.

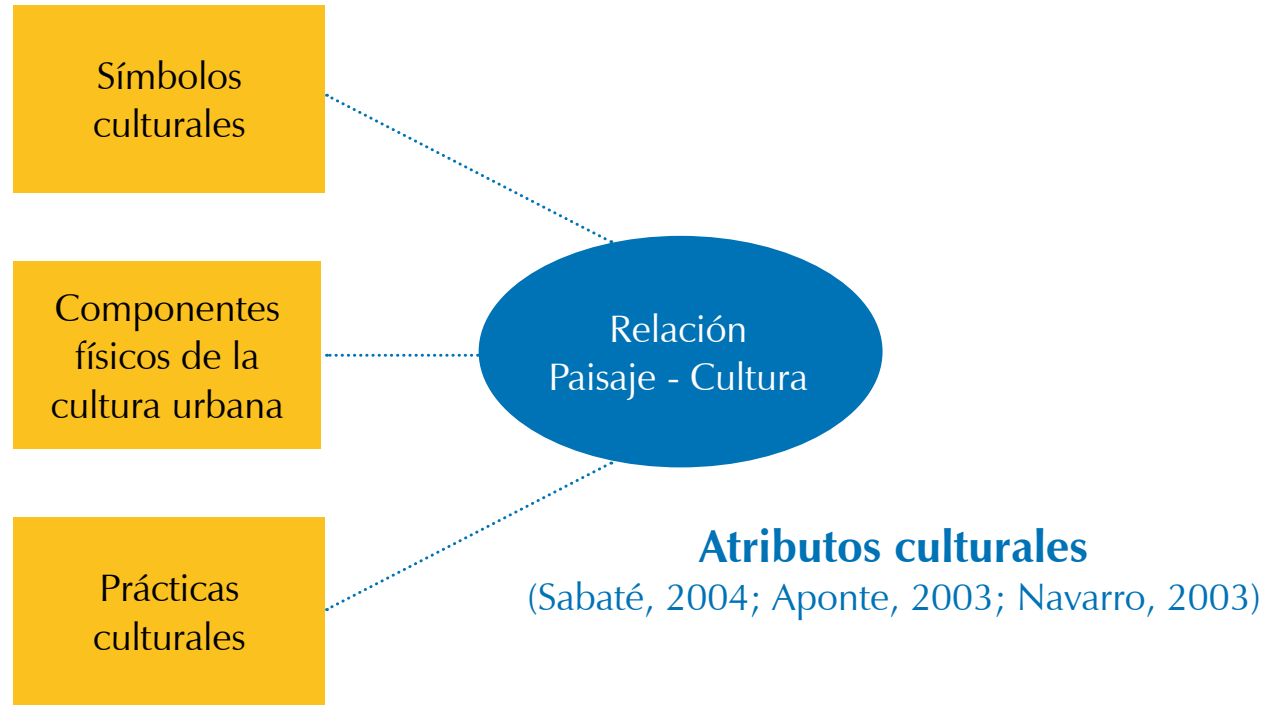

público en asentamientos informales, y que contribuyan al mejoramiento de la calidad de vida de las poblaciones más vulnerables (figura 5).

En la tabla 1 se muestra el listado inicial de los atributos e indicadores que ayudarán a evaluar la calidad visual del paisaje urbano, caracterizando los indicadores en tres atributos, seis componentes y dieciséis indicadores que serán los encargados de ayudar con la interpretación de los problemas espaciales del territorio, a nivel de paisaje.

Esta tabla muestra la información necesaria para la valoración diagnóstica de las áreas que se van a estudiar. El esquema triangular de los tipos de análisis del paisaje que se muestra en la figura 5 es el que define los grupos en los que se unen los tres atributos para evaluar la calidad del paisaje, como herramienta que determina el estado del espacio público por cada componente, con el fin de definir las principales falencias de dicho asentamiento.

En esta etapa de elaboración conceptual de los indicadores es necesario involucrar la participación de grupos comunitarios, académicos y al Gobierno, para generar una visión real y acertada de las formas de ocupación y utilización del territorio por parte de las comunidades más vulnerables de las principales ciudades, con el propósito de encontrar estrategias que consientan la correcta y efectiva implementación de los lineamientos, que permitan mejorar las condiciones de calidad de vida y de habitabilidad, a partir de conocer los principales conflictos, proponiendo para cada problema una solución puntual y realizable.

\section{DISCUSIÓN} de las culturas y es un importante instrumento de interpretación del territorio; con esa finalidad se han establecido las relaciones de los atributos desde áreas comunes para la ciudad, por medio de los indicadores que nos permitirán llegar a la interpretación de cuáles son las características de ocupación del territorio, a partir del modo de vida de las poblaciones, respondiéndonos a las preguntas: ¿cómo está conformado?, ¿en qué condiciones está?, ¿por qué es así?, con el fin de generar propuestas y estrategias que refuercen las deficiencias urbanas del espacio
Este documento busca dar continuidad a la discusión sobre el estudio del paisaje como elemento del mejoramiento del confort ambiental urbano, considerándolo como recurso ambiental, territorial y cultural, discusión generada a partir de las teorías y reflexiones de diferentes autores (Campo, 2003; Moreno, 2007; Amaya, 2005; Portal y Bonnet, 2011; Briceño et al., 2012; Fry et al., 2009; Sabate, 2004; Aponte, 2003; Navarro, 2003, Gómez, 2010; Masmela, 2010). 
Como respuesta a estos análisis, al hablar de lugares, espacios o paisajes, según el autor o la disciplina de análisis, queda en evidencia que no se puede mirar al paisaje solo como un fragmento de territorio, sino que se debe apreciar la interrelación que hay entre las acciones sociales y culturales de una población, poniendo fin a aquellas concepciones que miraban el paisaje como un inventario de elementos, donde la relación con el sujeto y su cultura viene a ser fundamental, y esta cultura en la que se desarrolla ese sujeto y su nivel de civilización van a determinar las características del paisaje (Navarro, 2003, p. 13).

En este sentido, el estudio del paisaje contribuiría a identificar, clasificar, valorar, mejorar y conservar los paisajes heredados, como herramienta de mejoramiento ambiental urbano, los cuales en muchos casos se destruyen o degradan debido a la falta de normativas que regulen el diseño, tanto arquitectónico como urbano, en función de la conservación del paisaje.

Debido a esto, el sistema de indicadores propuestos contribuirá a la sustentabilidad de la zona, mejorando las falencias encontradas en cada componente, preservando el significado que tiene cada lugar para la población, dando pautas acerca de cómo debería ser el diseño urbano, de manera que responda a los tres niveles de intervención mencionados a lo largo del texto, que serán determinantes a la hora de encaminar las propuestas de mejoramiento, lo que brindará una forma real de validar el sistema propuesto y de mejorar la calidad de vida de la población.

\section{CONCLUSIONES}

Este texto permite identificar unos principios de análisis a través de la revisión del estado del arte referente a estudios de paisaje, por medio de los cuales se han establecido los atributos y componentes que ayudarán a evaluar la situación del paisaje urbano. Sus diferentes definiciones y análisis dejan en evidencia la relevancia que se le da a la significación del territorio y al simbolismo que tiene determinada porción de terreno que está cargado por nuestras relaciones sociales; recalca también que no se puede estudiar el paisaje como un área geográfica, sino, por el contrario, se debe asignar valor a aquellos espacios o lugares dentro de la ciudad que reúnen la mayor cantidad de simbolismos para los habitantes.

En este sentido, la propuesta de indicadores a partir de variables que evalúan la calidad del paisaje en asentamientos informales muestra la información necesaria para la valoración diagnóstica del área por estudiar, con el fin de determinar el estado de cada componente, para poder establecer en detalle cuáles son las principales carencias y falencias encontradas en estos asentamientos, permitiendo detectar los puntos estratégicos en los cuales se puede proyectar una propuesta de mejoramiento mediante un diseño urbano que incorpore los aspectos estudiados.

De este modo, los atributos aquí conceptualizados ayudan a identificar cuáles son los elementos implicados en el mejoramiento de la calidad del paisaje de un asentamiento informal a partir del desarrollo de estos indicadores, buscando proponer una intervención urbana sustentada en el diseño urbano del espacio público, sujeta al mejoramiento y la intervención del entorno construido de acuerdo con las necesidades y tradiciones de las comunidades.

Este sistema de evaluación de la calidad del paisaje es un aporte en la formulación de estrategias para el acondicionamiento del hábitat urbano informal en nuestro país, ya que muestra un sistema de evaluación y valoración de una zona determinada, en donde se puedan enfocar nuevas acciones urbanísticas para cualquier asentamiento de origen informal, por medio de normas que regulen el diseño urbano en función del paisaje, a fin de evitar la aparición de usos que alteren las dinámicas espaciales o que perturben las visuales en el entorno. Es fundamental tener en cuenta los aspectos culturales y las relaciones que existen en el espacio construido, ya que los indicadores formulados parten de la necesidad de buscar los valores asociados del paisaje para determinada población, encontrando un adecuado equilibrio entre los atributos estudiados, a fin de lograr una buena planificación territorial o, como en el caso de esta investigación, de un apropiado diseño urbano.

En concordancia con lo anterior, y para garantizar la diversidad de las manifestaciones culturales de las comunidades en una construcción colectiva de ciudad, es importante definir un modelo a partir de los diferentes imaginarios culturales que habitan, de tal forma que las manifestaciones morfológicas - ya sea de espacios urbanos o de las edificaciones que los conforman- sean a su vez contenedoras de expresiones culturales que reflejen las necesidades y preferencias de las comunidades, para conformar barrios menos vulnerables que muestren una vía de cómo puede resolverse un problema de informalidad en un sector marginado de cualquier ciudad del país. 


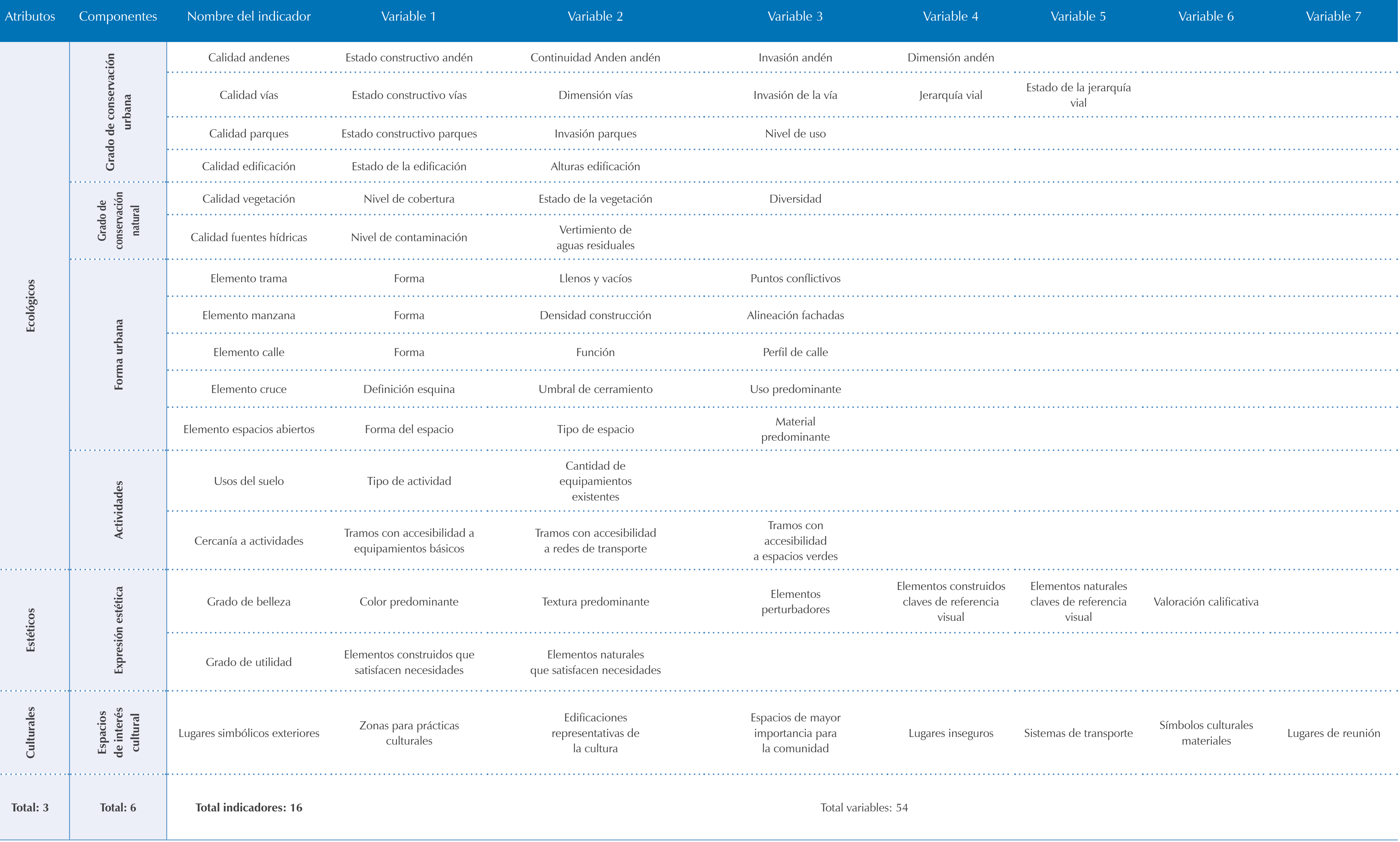




\section{REFERENCIAS}

Acuña, V. P. (2005). Análisis formal del espacio urbano. Lima: Instituto de Investigación de la Facultad de Arquitectura Urbanismo y Artes.

Álvarez, M. L. (2011). La categoría del paisaje cultural. Revista de Antropología Iberoamericana, 6 (1) 57-80.

Amaya, H. C. (2005). El ecosistema urbano: simbiosis entre lo natural y lo artificial. Revista Forestal Latinoamericana, 37, 1-16.

Aponte, G. G. (2003). Paisaje e identidad cultural. Revista humanidades. Tabula Rasa, 1.

Arias, S. P, (2001). El problema del paisaje en los actúales desarrollos periféricos urbanos, departamento de urbanística y ordenación del territorio. Tesis doctoral: Escuela Técnica Superior de Arquitectura. Universidad de Sevilla [en línea]. Recuperado de: http:// fondosdigitales.us.es/tesis/tesis/1800/el-problema-del-paisaje-en-los-actuales-desarrollos-suburbanos/\#description

Arias, S. P. (2003). Periferias y nueva ciudad: e problema del paisaje en los procesos de dispersión urbana. Secretariado de Publicaciones de la Universidad del Sevilla [en línea]. Recuperado de: http://www.kilibro.com/ book/preview/30344_periferias-y-nuevaciudad

Arias, O. S. (2013). Desarrollo sustentable de la arquitectura turística en ciudades costeras, una visión desde el paisaje, el territorio y la ciudad. Revista de Arquitectura, Urbanismo y Ciencias Sociales, IV (1), 85, 87.

Arango, E. G. (1990). La ciudad informal del siglo $X X I$. En Foro perspectivas metropolitanas siglo XX, Universidad Nacional de Colombia sede Medellín [en línea]. Recuperado de: http://www.bdigital.unal.edu.co/3003/

Berque, A. (2006). Paisaje y Ecúmene. Seminario Internacional de teoría del paisaje. Maestría Paisaje, Medioambiente y Ciudad. Universidad Nacional de La Plata, Facultad de Arquitectura y Urbanismo.

Bertand, G. (1968) Paysage et Géographie physique globales, Esquisse methodologique. Revue Géographique des Pyrénées et du sud - Quest T. XXXIX, 39 (3) 249-272. Recuperado de http://www.persee.fr/doc/rgpso_0035-3221_1968_num_39_3_4553

Boira, M. J. (1987). La vivencia del espacio urbano. La creación de imágenes en la relación hombre-ciudad. Cuadernos de geografía, 41, 93-106.

Brakarz, J., Greene, M. y Rojas, E. (2002). Ciudades para todos, la experiencia reciente en programas de mejoramiento de barrios. Washington D.C.: BID.

Briceño, Á. M., Contreras, M. W. y Owen de Contreras, M. (2012). Atributos eco-estéticos del paisaje urbano. Revista Luna Azul, 34.
Briceño, Á. M. (2002). La percepción visual de los objetos del espacio urbano. Análisis del sector El Llano, del área central de la ciudad de Mérida. Revista Fermentum, 12 (33) [en línea]. Recuperado de: http://www.redalyc. org/articulo.oa?id=70511244006

Briceño, A. M. (2009). El valor estético y ecológico del paisaje urbano y los asentamientos humanos sustentables. Revista Geográfica Venezolana, 50 (2), 213-233.

Briceño, A. y Gil, B. (2005). intervención sobre la imagen urbana en centros tradicionales, proyecto de renovación urbana: Funicular-Trobelus, Mérida, Venezuela. Fermetum - Revista Venezolana de Sociología y Antropología, 15 (44), 367-397.

Busquets, J. (1999). La urbanización marginal 2. Universidad Politécnica de Cataluña [en línea]. Recuperado de: http://books.google. com.co/books? id =u06bvTMncAgC\&prints $\mathrm{ec}=$ frontcover $\& \mathrm{hl}=\mathrm{es} \# \mathrm{v}=$ onepage $\& \mathrm{q} \& \mathrm{f}=$ false

Caquimbo, S. S. (2010). Variables para la construcción de paisaje habitacional. Cuadernos de Vivienda y Urbanismo, 3 (6), 196-219.

Campo, R. O. (2003). Del paisaje a la ciudad. Revista bitácora, urbano territorial, 7 (1), 44-52.

Chaparro, V. J. (2004). Elaboración y gestión de planes de manejo para paisajes culturales, estudio de caso: Paisaje Cultural Cafetero. Curso-taller Internacional, Universidad Nacional de Colombia, Manizales.

Clichevsky, N. (2000). Informalidad y segregación urbana en América Latina. Una aproximación. Serie: medioambiente y desarrollo. Santiago de Chile: Ministero degli Affari Esteri (Italia) y NU-CEPAL. Recuperado de: http://repositorio.cepal.org/ bitstream/handle/11362/5712/S00100859 es.pdf?sequence $=1$

Curtis, B. y Massarini, A. (2007). Biología (7 ed.). Bogotá: Editorial Médica Panamericana [en línea]. Recuperado de: http://www.curtisbiologia.com/node/1831

Davis, M. (2006). El planeta de los tugurios. Revista Temas, Cultura, Ideología y Sociedad (48), 4-15

Real Academia Española (2001). Diccionario de la Lengua Española. Madrid: Espasa Calpe.

Dos Santos, P. (2011). Marco teórico-metodológico de los estudios del paisaje: perspectivas de aplicación en la planificación del turismo. Estudios y Perspectivas en turismo 20 (3). 522-541. Universidad do Vale do Itaja-Camboriu - Brasil. Recuperado de http://www.estudiosenturismo.com.ar/PDF/ V20/N03/v20n3a01.pdf
Duhau, E. (2003). La ciudad informal. El orden urbano y el derecho a la ciudad. Trabajo presentado en el congreso de Anpur, Bello Horizonte, Universidad Autónoma Metropolitana, Azcapotzalco.

Escribano, M. M. (1989). El Paisaje. Madrid: Ministerio de Obras Públicas.

Fighera, D. T. (2005). Paisaje natural, Paisaje Humanizado o Simplemente paisaje. Revista Geográfica Venezolana, 4 (1), 113-118.

Forman, R. T. (2004). Mosaico territorial para la región metropolitana de Barcelona. Barcelona: Gustavo Gili.

Fry, G., Tveit, M. S., Ode, A. y Velarde, M. D. (2009). The ecology of visual landscapes: Exploring the conceptual common ground of visual and ecological landscape indicators. Journal of Ecological Indicators, 9, 933-947 [en línea]. Recuperado de: http:// www.sciencedirect.com/science/article/pii/ S1470160X08001581

Garre, F. (2001). Patrimonio arquitectónico urbano, preservación y rescate: bases conceptuales e instrumentos de salvaguarda. Revista conserva (5).

Gómez A. A. (2010). El paisaje como patrimonio cultural, ambiental y productivo, análisis e intervención para su sostenibilidad. Revista KEPES, 7 (6), 91-106.

Gurrutxaga, M. y Lozano, P. (2008). Ecología del paisaje. Un marco para el estudio integrado de la dinámica territorial y su incidencia en la vida silvestre. Revista Estudios Geográficos, LXIX (265), 519-543.

Hernández, C. N. (2007). Insostenibilidad y sostenibilidad en el desarrollo de la vivienda informal. En Herrera, M. (ed.). Procesos urbanos informales y territorios, ensayos en torno a la construcción de sociedad, territorio y ciudad (pp. 47-58). Bogotá: Universidad Nacional de Colombia.

Hernández, B. M. (2008). Procesos informales del espacio público en el hábitat popular. Revista Bitácora, 13, 109-116.

Khzam, D. E. (2008). La percepción ambiental como significado del paisaje: implicancias teóricas desde la relación del ser humano y el entorno. Revista Electrónica Ambiente Total. Ecología, Geografía, Urbanismo y Paisaje, 1.

Lerma, R. E. (2013). Espacio vivido: del espacio local al reticular. Notas en torno a la representación social del espacio vivido en la globalización. Revista Pueblos y fronteras digitales, 8 (15), 225-250.

Liernur, J. F. (2004). La belleza urbana como construcción colectiva. Apuntes sobre el espacio público en Buenos Aires. Revista Todavía (9). 
Lombo, T. R. (1998). Ecología y usos del suelo. Bogotá: Sociedad Geográfica de Colombia, Academia de Ciencias Geográficas.

Lynch, K. (1992). La administración del paisaje. Bogotá: Norma.

Martignoni, J. (2009). El paisaje como referente de diseño. Cuaderno 30, centro de estudios en diseño y comunicación, 10 (30), 9-20.

Martorell, C. A. (2003). Paisajes e itinerarios culturales: conceptos independientes que enriquecen la teoría y la práctica de la conservación cultural. The CIIC Scientific Magazine (2) Recuperado de: http://www. esicomos.org/Nueva carpeta/TCSM/ponencia_AMARTORELL.htm

Masmela, D. P. (2010). El paisaje como elemento de la ordenación territorial. Un análisis del paisaje desde su enfoque visual en el borde centro-oriental de Medellín, Colombia. Trabajo de tesis de Maestría, Universidad Nacional de Colombia, Medellín.

Matteucci, S. (2009). Ecología del paisaje: conceptos, historia, campos de aplicación. Grupo de Ecología del Paisaje Urbano y Medio Natural (Gepama). Recuperado de: http://www.gepama.com.ar/ index.php?option $=$ com_content\&view $=$ ar ticle\&id=13: ecologia-de-paisajes\&catid $=9$ :investigaciones\&ltemid $=17$.

McHarg, I. L. (2000). Proyectar con la naturaleza. Barcelona: Gustavo Gili.

Meda, H. R. (2011). Ficha $N^{\circ} 13$ del taller, diseño urbano, taller vertical Meda. Facultad de Arquitectura y Urbanismo, Universidad Nacional de La Plata [en línea]. Recuperado de: http://blogs.unlp.edu.ar/planeamientofau/files/2013/07/Ficha-13-DISE\%C3\%91OURBANO.pdf

Moreno, F. O. (2007). Paisaje: plataforma de comprensión gestión de las dinámicas del ambiente y del territorio. Santiago: Universidad de Chile. Recuperado de: http://repositorio.uchile.cl/handle/2250/118055

Morgan, B. D. (2006). Los usuarios del espacio público como protagonistas en el paisaje urbano. Revista de Arquitectura, 8 (1), 34-41.

Morlans, M. C. (2005). Introducción a la ecología del paisaje. Área ecológica. Catamarca: Editorial Científica Universitaria, Universidad Nacional de Catamarca.

Muñoz, P. A. (2004). La evaluación del paisaje: una herramienta de gestión ambiental. Revista chilena de historia natural, 77 (1), 139-156 [en línea]. Recuperado de: http://www.scielo.cl/scielo.php?pid=s0716078x2004000100011\&script =sci_arttext.

Navarro, B. G. (2003). Una aproximación al paisaje como patrimonio cultural, identidad y constructo mental de una sociedad. Apuntes para la búsqueda de invariantes que determinen la patrimonialidad de un paisa- je. Santiago: Facultad de Arquitectura y Paisaje, Universidad de Chile.

Niño, B. R. (2006). Indicadores estéticos de cultura urbana. Bogotá: Editorial Pontificia Universidad Javeriana. Facultad de Arquitectura y Diseño, Departamento de Estética.

Ojeda, L. C. (2011). Estado del arte en las conceptualizaciones del paisaje y el paisaje urbano. Una revisión bibliográfica. Concepción: Universidad de Concepción.

Perahia, R. (2007). Las ciudades y su espacio público. IX coloquio internacional de geocrítica, los problemas del mundo actual, soluciones y alternativas desde la geografía y las ciencias sociales. Porto Alegre, Universidad Federal do Rio Grande do Sul.

Pérez, E. (2000). Paisaje urbano en nuestras ciudades. Revista Bitácora, Urbano/Territorial, 4 (1), 33, 34.

Pérgolis, J. C. (2002). Bogotá fragmentada. Cultura y espacio urbano a fines del siglo XX. En Ciudad, memoria y recorrido. Mérida: Humanic-ULA, Editorial Venezolana.

Portal, M. M. y Bonnet, P. C. (2011). Cartografías de la calidad visual del entorno construido en el barrio El Almendral, ciudad patrimonial Valparaíso. Revista geográfica de Valparaíso (44), 18-33.

Rebotier, J. (2010). La informalidad y su construcción, indicador e instrumentos de relaciones y transformaciones sociales en Caracas. México: Taller Recim.

Rodríguez, M. (2003). Estudios de arquitectura bioclimática. Anuario 2003, V (pp. 104,105). México: Universidad Autónoma Metropolitana.

Rojas, P. (2007). Relatorías Eje paisajes culturales, una aproximación conceptual: paisaje cultural. XXCII Reunión Comité Sectorial de Cultura - UCCI.

Rozo, B. V. (2011). Valores locales y problemas ambientales: Asentamientos de origen informal. Revista N-AERUS XII. 20-22/10. Recuperado de: http://n-aerus.net/web/ sat/workshops/2011/PDF/N-AERUS_XII Rozo\%20Barajas_Viviana_RV.pdf

Sabate, B. J. (2004). De la preservación del patrimonio a la ordenación del paisaje. Urbano, 1 (10), 42-49.

Sáez, E., García J. y Roch F. (2010). La ciudad desde la casa: ciudades espontáneas en Lima. Revista INVI, 25 (70), 77-116.

Salas, M. (1999). Urbanismo y planes especiales. Mérida: Universidad de los Andes, Consejo de Publicaciones, Consejo de Estudios de Posgrado.

Salas, S. J. (2005). Mejora de barrios precarios en Latinoamérica. Elementos de teoría y práctica. Revista Escala.
Saldarriaga, A. (2002). La ciudad informal y futuro de la ciudad colombiana. Ponencia en el Foro sobre Hábitat, agosto de 2002, Universidad La Gran Colombia, Bogotá.

Santos, L. (2003). Las nociones del paisaje y sus implicaciones en la ordenación. Revista ciudades, 7, 41-68.

Santos, M. (2000). La naturaleza del espacio. Técnica y tiempo. Razón y emoción. Barcelona: Ariel.

Segovia, O. y Oviedo, E. (2000). Espacios públicos en la ciudad y el barrio. En Espacio públiCo, participación y ciudadanía. Santiago de Chile: Ediciones SUR [en línea]. Recuperado de: http://www.sitiosur.cl/r.php?id=298

Saule, N. J. (2008). Derecho a la ciudad como respuesta estratégica a la exclusión social y a la segregación espacial. En Desafíos de la construcción democrática en Brasil, el derecho a la ciudad (pp. 39-82). Brasil.

Steiner, F. (2008). The living landscape. An ecological approach to landscape planning (2 ed.). EE.UU.: Island Press.

Tesser, O. C. (2000). Algunas reflexiones sobre los significados del paisaje para la geografía. Revista de Geografía Norte Grande, 27, 19-26.

Torres, T. C. (2007). Ciudad informal colombiana. Revista bitácora urbano territorial, 1 (11).

UN-Habitat/Rolac, (2004), Oficina regional para América Latina y el Caribe: UNHabitat. Programa de las naciones unidas para los asentamientos Humanos. http:// es.unhabitat.org/

Unesco (1972). Convención sobre la protección del patrimonio mundial, cultural y natural.

Vila, S., Vargas, L. y Ribas, P. (2006). Conceptos y métodos fundamentales en ecología del paisaje (landscape ecology). Una interpretación desde la geografía. Documents d'Anàlisi Geogràfica, 48.

Viqueira, J. P. (1994). Regiones naturales, regiones nominales y regiones vividas [en línea]. Recuperado de: http://cdigital.uv.mx/ bitstream/123456789/8773/1/sotav3Pag107-117.pdf

Villarino, M. T. (1985). Curso sobre evaluación de impacto ambiental, dirección general del medio ambiente. Madrid: M.O.P.U.

Zárate, M. A. (2010). Paisajes culturales urbanos, un legado para conservar. Revista Anales de Geografía, 30 (2), 187-210. 
La postulación de un artículo a la Revista de Arquitectura indica que- el o los autores certifican que conocen y aceptan la política editorial, para lo cual firmarán en original y remitirán el formato RevArq FP00 Carta de originalidad.

La Revista de Arquitectura maneja una política de Autoarchivo VERDE, según las directrices de SHERPA/RoMEO, por lo cual el autor puede:

Pre-print del autor: Archivar la versión pre-print (la versión previa a la revisión por pares)

Post-print del autor: Archivar la versión post-print (la versión final posterior a la revisión por pares)

Versión de editor/PDF: Archivar la versión del editor - PDF/HTML/XLM en la maqueta de la Revista de Arquitectura.

El Autoarchivo se debe hacer respetando la licencia de acceso abierto, la integridad y la imagen de la Revista de Arquitectura, también se recomienda incluir la referencia, el vínculo electrónico y el DOI.

El autor o los autores son los titulares del Copyright (c) del texto publicado y la Editorial de la Revista de Arquitectura solicita la firma de una autorización de reproducción del artículo (RevArq FP03 Autorización reproducción), la cual se acoge a la licencia CC, donde se expresa el derecho de primera publicación de la obra.

La Revista de Arquitectura se guía por las normas internacionales sobre propiedad intelectual y derechos de autor, y de manera particular el artículo 58 de la Constitución Política de Colombia, la Ley 23 de 1982 y el Acuerdo 172 del 30 de septiembre de 2010 (Reglamento de propiedad intelectual de la Universidad Católica de Colombia).

Para efectos de autoría y coautoría de artículos se diferencian dos tipos: "obra en colaboración" y "obra colectiva". La primera es aquella cuya autoría corresponde a todos los participantes al ser fruto de su trabajo conjunto. En este caso, quien actúa como responsable y persona de contacto debe asegurar que quienes firman como autores han revisado y aprobado la versión final, y dan consentimiento para su divulgación. La obra colectiva es aquella en la que, aunque participan diversos colaboradores, hay un autor que toma la iniciativa, la coordinación y realización de dicha obra. En estos casos, la autoría corresponderá a dicha persona (salvo pacto en contrario) y será suficiente únicamente con su autorización de divulgación.

El número de autores por artículo debe estar justificado por el tema, la complejidad y la extensión, y no deberá ser superior a la media de la disciplina, por lo cual se recomienda que no sea mayor de cinco. El orden en que se enuncien corresponderá a los aportes de cada uno a la construcción del texto, se debe evitar la autoría ficticia o regalada. Si se incluyen más personas que trabajaron en la investigación se sugiere que sea en calidad de colaboradores o como parte de los agradecimientos. La Revista de Arquitectura respetará el número y el orden en que figuren en el original remitido. Si los autores consideran necesario, al final del artículo pueden incluir una breve descripción de los aportes individuales de cada uno de firmantes.

La comunicación se establece con uno de los autores, quien a su vez será el responsable de informar a los demás autores de las notificaciones emitidas por la Revista de Arquitectura.

En virtud de mantener el equilibro de las secciones y las mismas oportunidades para todos los participantes, un mismo autor puede postular dos o más artículos de manera simultánea; si la decisión editorial es favorable y los artículos son aceptados, su publicación se realizará en números diferentes.

\section{(A) ACCESO ABIERTO}

La Revista de Arquitectura, en su misión de divulgar la investigación y apoyar el conocimiento y la discusión en los campos de interés, proporciona acceso abierto, inmediato e irrestricto a su contenido de manera gratuita mediante la distribución de ejemplares impresos y digitales. Los interesados pueden leer, descargar, guardar, copiar y distribuir, imprimir, usar, buscar o referenciar el texto completo o parcial de los artículos o la totalidad de la Revista de Arquitectura.

\section{(c) (1) (9)}

Esta revista se acoge a la licencia Creative Commons (CC BYNC de Atribución - No comercial 4.0 Internacional): "Esta licencia permite a otros entremezclar, ajustar y construir a partir de su obra con fines no comerciales, y aunque en sus nuevas creaciones deban reconocerle su autoría y no puedan ser utilizadas de manera comercial, no tienen que estar bajo una licencia con los mismos términos".

La Revista de Arquitectura es divulgada en centros y grupos de investigación, en bibliotecas y universidades, y en las principales facultades de Arquitectura, mediante acceso abierto a la versión digital y suscripción anual al ejemplar impreso o por medio de canje, este último se formaliza mediante el formato RevArq FP20 Canjes.

Para aumentar su visibilidad y el impacto de los artículos, se envían a bases de datos y sistemas de indexación y resumen (SIR) y, asimismo, pueden ser consultados y descargados en la página web de la revista.

La Revista de Arquitectura no maneja cobros, tarifas o tasas de publicación de artículo (Article Processing Charge-APC), o por el sometimiento de textos a la publicación.

\section{(1ÉTICA Y BUENAS PRÁCTICAS}

La Revista de Arquitectura se compromete a cumplir y respetar las normas éticas en todas las etapas del proceso de publicación. Los autores de los artículos publicados darán cumplimiento a los principios éticos contenidos en las diferentes declaraciones y legislaciones sobre propiedad intelectual y derechos de autor específicos del país donde se realizó la investigación. En consecuencia, los autores de los artículos postulados y aceptados para publicar, que presentan resultados de investigación, deben firmar la declaración de originalidad (formato RevArq FP00 Carta de originalidad).

La Revista de Arquitectura reconoce y adopta los principios de transparencia y buenas prácticas descritos por COPE, "Principles of Transparency and Best Practice in Scholarly Publishing" (2015).

El equipo editorial tiene la obligación de guardar la confidencialidad acerca de los artículos recibidos, y abstenerse de usar en sus propias investigaciones datos, argumentos o interpretaciones hasta tanto el artículo no sea publicado. También debe ser imparcial y gestionar los artículos de manera adecuada y en los plazos establecidos. La selección de revisores se hará con objetividad y estos deberán responder a la temática del artículo.

El editor, los autores y los revisores deben seguir las normas éticas internacionales definidas por el Committee on Publication Ethics (COPE), con el fin de evitar casos de:

- Fabricación, falsificación u omisión de datos.

- Plagio y autoplagio.

- Publicación redundante, duplicada o fragmentada.

- Omisión de referencias a las fuentes consultadas.

- Utilización de contenidos sin permiso o sin justificación.

- Apropiación individual de autoría colectiva.

- Cambios de autoría.

- Conflicto de interés (CDI) no revelado o declarado.

- Otras que pudieran surgir en el proceso de investigación y publicación. La fabricación de resultados se genera al mostrar datos inventados por los autores; la falsificación resulta cuando los datos son manipulados y cambiados a capricho de los autores; la omisión se origina cuando los autores ocultan deliberadamente un hecho o dato. El plagio se da cuando un autor presenta como ideas propias datos creados por otros. Los casos de plagio son los siguientes: copia directa de un texto sin entrecomillar o citar la fuente, modificación de algunas palabras del texto, paráfrasis y falta de agradecimientos; el autoplagio se da cuando el mismo autor reutiliza material propio que ya fue publicado, pero sin indicar la referencia al trabajo anterior. La revista se apoya en herramientas digitales que detectan cualquiera de estos casos en los artículos postulados, y es labor de los editores y revisores velar por la originalidad y fidelidad en la citación. La publicación redundante o duplicada se refiere a la copia total, parcial o alterada de un trabajo ya publicado por el mismo autor

En caso de sospechar de alguna mala conducta se recomienda seguir los diagramas de flujo elaborados por COPE (2008), con el fin de determinar las acciones correspondientes.

La Revista de Arquitectura se reserva el derecho de retractación de publicación de aquellos artículos que, posterior a su publicación, se demuestre que presentan errores de buena fe, o cometieron fraudes o malas prácticas científicas. Esta decisión se apoyará en "Retraction Guidelines" (COPE, 2009). Si el error es menor, este se podrá rectificar mediante una nota editorial de corrección o una fe de erratas. Los autores también tienen la posibilidad de solicitar la retractación de publicación cuando descubran que su trabajo presenta errores graves. En todos los casos se conservará la versión electrónica y se harán las advertencias de forma clara e inequívoca.

\section{A PRIVACIDAD Y MANEJO DE LA INFORMACIÓN.} HABEAS DATA

Para dar cumplimiento a lo previsto en el artículo 10 del Decreto 1377 de 2013, reglamentario de la Ley 1581 de 2012, y según el Acuerdo 002 del 4 de septiembre de 2013 de la Universidad Católica de Colombia, "por el cual se aprueba el manual de políticas de tratamiento de datos personales"

La Universidad Católica de Colombia, considerada como responsable o encargada del tratamiento de datos personales, manifiesta que los datos personales de los autores, integrantes de los comités y pares revisores, se encuentran incluidos en nuestras bases de datos; por lo anterior, y en cumplimiento de las disposiciones legales vigentes, la Universidad solicitará siempre su autorización, para que en desarrollo de sus funciones propias como Institución de Educación Superior, en especial las relacionadas con la docencia, la extensión y la investigación, la Universidad Católica de Colombia pueda recolectar, recaudar, almacenar, usar, circular, suprimir, procesar, intercambiar, compilar, dar tratamiento, actualizar, transmitir o transferir a terceros países y disponer de los datos que le han suministrado y que han sido incorporados en las bases de datos de todo tipo que reposan en la Universidad.

La Universidad Católica de Colombia queda autorizada, de manera expresa e inequívoca, en los términos señalados por el Decreto 1377 de 2013, para mantener y manejar la información de nuestros colaboradores (autores, integrantes de los diferentes comités y pares revisores); así mismo, los colaboradores podrán ejercer sus derechos a conocer, actualizar, rectificar y suprimir sus datos personales, para lo cual se han dispuesto las siguientes cuentas de correo electrónico: 
La Revista de Arquitectura recibe artículos de manera permanente. Los artículos se procesan a medida que se postulan, dependiendo el flujo editorial de cada sección.

El idioma principal es el español, y como opcionales están definidos el inglés, el portugués y el francés; los textos pueden ser escritos y presentados en cualquiera de estos.

Los artículos postulados deben corresponder a las categorías universalmente aceptadas como producto de investigación, ser originales e inéditos y sus contenidos responder a criterios de precisión, claridad y brevedad.

Como punto de referencia se pueden tomar las tipologías y definiciones del Índice Bibliográfico Nacional, Publindex (2010) que se describen la continuación:

1. Artículo de revisión: documento resultado de una investigación terminada donde se analizan, sistematizan e integran los resultados de investigaciones publicadas o no publicadas, sobre un campo en ciencia o tecnología, con el fin de dar cuenta de los avances y las tendencias de desarrollo. Se caracteriza por presentar una cuidadosa revisión

bibliográfica de por lo menos 50 referencias.
2. Artículo de investigación científica y tecnológica: documento que presenta, de manera detallada, los resultados originales de proyectos terminados de investigación. La estructura generalmente utilizada contiene cuatro apartes importantes: introducción, metodología, resultados y conclusiones.

3. Artículo de reflexión: documento que presenta resultados de investigación terminada desde una perspectiva analítica, interpretativa o crítica del autor, sobre un tema específico, recurriendo a fuentes originales.

En todos los casos se debe presentar la información suficiente para que cualquier investigador pueda reproducir la investigación y confirmar o refutar las interpretaciones defendidas.

También se pueden presentar otro tipo de documentos diferentes a los anteriormente descritos, como pueden ser: artículo corto, reporte de caso, revisión de tema, documento resultado de la revisión crítica de la literatura sobre un tema en particular, cartas al editor, traducción, documento de reflexión no derivado de investigación, reseña bibliográfica, así como proyectos de arquitectura o urbanismo, entre otros

\section{A INSTRUCCIONES PARA POSTULAR ARTÍCULOS}

Postular el artículo en la página web de la Revista de Arquitectura y adjuntar comunicación escrita dirigida al editor RevArq_FP00 Carta de originalidad (debidamente firmada por todos los autores en original); de igual manera, se debe diligenciar el formato de hoja de vida RevArq FP01 Hoja de Vida (una por cada autor).

En la comunicación escrita el autor expresa que conoce y acepta la política editorial de la Revista de Arquitectura, que el artículo no está postulado para publicación simultáneamente en otras revistas u órganos editoriales y que no existe conflicto de intereses (ver modelo RevArq FP06 CDI) y que, de ser aceptado, concederá permiso de primera publicación, no exclusiva a nombre de la Universidad Católica de Colombia como editora de la revista.

Los artículos deben tener en cuenta las siguientes recomendaciones:

- En la primera página del documento se debe incluir:

TítUlo: no exceder 15 palabras.

Subtítulo: opcional, complementa el título o indica las principales subdivisiones del texto.

NOMBRE DEL AUTOR O AUTORES: nombres y apellidos completos o según modelo de citación adoptado por el autor para la normalización de los nombres del investigador. Como nota al pie (máximo 150 palabras): formación académica, experiencia profesional e investigativa, vinculación laboral, premios o reconocimientos, publicaciones representativas e información de contacto, correo electrónico.

FILIACIÓN INSTITUCIONAL: debajo del nombre se debe declarar la inV titución en la cual se desarrolló el producto, de la cual recibió apoyo o aquella que respalda el trabajo investigativo.

RESUMEN: debe ser analítico, se redacta en un solo párrafo, da cuenta del tema, el objetivo, la metodología, los resultados y las conclusiones; no debe exceder las 150 palabras.

PALABRAS CLAVE: cinco palabras o grupo de palabras, ordenadas alfabéticamente y que no se encuentren en el título o subtítulo; estas sirven para clasificar temáticamente al artículo. Se recomienda emplear principalmente palabras definidas en el tesauro de la Unesco (http:// databases.unesco.org/thessp/) o en el tesauro de Arte \& Arquitectura (C) (www.aatespanol.cl).

También se recomienda incluir título, resumen y palabras clave en segundo idioma.

- La segunda página y siguientes deben tener en cuenta:

El cuerpo del artículo generalmente se divide en: Introducción, Metodología, Desarrollo, Resultados y Discusión de resultados; posteriormente se presentan las Conclusiones, y luego las Referencias bibliográficas y los Anexos (método IMRYD). Las tablas y figuras se deben incorporar en el texto.

DESCRIPCIÓN DEL PROYECTO DE INVESTIGACIÓN: en la introducción se debe describir el tipo de artículo y brevemente el marco investigativo del cual es resultado y diligenciar el formato (RevArq FP02 Info Proyectos de Investigación).

TEXTO: todas las páginas deben venir numeradas y con el título de artículo en la parte inferior (pie de página). Márgenes de $3 \mathrm{~cm}$ por todos los lados, interlineado doble, fuente Arial o Times New Roman de 12 puntos, texto justificado (Ver plantilla para presentación de artículos). La extensión de los artículos debe ser de alrededor de 5.000 palabras ( \pm 20 páginas, incluyendo gráficos, tablas, referencias, etc.); como mínimo 3.500 y máximo 8.000 palabras. Se debe seguir el estilo vigente y recomendado en el Manual para Publicación de la American Psychological Association (APA). (Para mayor información véase http://www.apastyle.org/)
CITAS Y NOTAS AL PIE: las notas aclaratorias o notas al pie no deben exceder cinco líneas o 40 palabras, de lo contrario estas deben ser incorporadas al texto general. Las citas pueden ser:

Corta: (con menos de 40 palabras) se incorporan al texto y pueden ser: textuales (se encierran entre dobles comillas), parafraseo o resumen (se escriben en palabras del autor dentro del texto).

Cita textual extensa: (mayor de 40 palabras) debe ser dispuesta en un renglón y un bloque independiente con sangrías y omitiendo las comillas, no olvidar en ningún caso la referencia del autor (Apellido, año, página).

REFERENCIAS: como modelo para la construcción de referencias se emplea el estilo recomendado en el Manual para Publicación de la American Psychological Association (APA) (http://www.apastyle.org/).

SIGLAS: en caso de emplear siglas en el texto, las figuras o las tablas, se debe proporcionar la equivalencia completa la primera vez que se empleen y encerrarlas entre paréntesis. En el caso de citar personajes reconocidos se deben colocar nombres o apellidos completos, nunca emplear abreviaturas.

GRÁFICOS Y TABLAS: las figuras (gráficos, diagramas, ilustraciones, planos, mapas o fotografías) y las tablas deben ir numeradas y contene título o leyenda explicativa relacionada con el tema del artículo, que no exceda las 15 palabras (Figura 1. xxxxx, Tabla 1. xxxx, etc.) y la procedencia (fuente: autor o fuente, año, página). Estas se deben citar en e texto de forma directa o entre paréntesis; se recomienda hacerlo con referencias cruzadas.

También se deben entregar en medio digital, independiente del texto, en formatos editables o abiertos. La marcación de los archivos debe corresponder a la incluida en el texto. Según la extensión del artículo se deben incluir de 5 a 10 gráficos. Ver guía para la búsqueda de imágenes de dominio público o bajo licencias Creative Commons (CC).

El autor es el responsable de adquirir los derechos o las autorizaciones de reproducción a que haya lugar para imágenes o gráficos tomados de otras fuentes, así como de entrevistas o material generado por colaboradores diferentes a los autores; de igual manera, se debe garantizar la protección de datos e identidades para los casos que sea necesario.

FOTOGRAFíA: pueden ser entregadas en original para ser digitalizadas, de lo contrario se deben digitalizar con una resolución igual o superior a 300 dpi para imágenes a color y 600 para escala de grises. Los formatos de las imágenes pueden ser TIFF, PSD o JPG, y deben cumplir con las características expresadas en el punto anterior (gráficos).

PLANIMETRÍA: se debe entregar la planimetría original en medio digital en lo posible en formato CAD, y sus respectivos archivos de plumas o en PDF; de no ser posible, se deben hacer impresiones en tamaño carta con las referencias de los espacios mediante numeración y lista adjunta. Deben tener escala gráfica, escala numérica, norte, coordenadas y localización. En lo posible, no deben contener textos, achurados o tramas.

Para más detalles, consultar el documento RevArq Parámetros para Autores Descripción en el portal web de la Revista de Arquitectura

\section{Beneficios}

Como reconocimiento a los autores, se les hará envío postal de dos ejemplares de la edición impresa sin ningún costo y entregada en la dirección consignada en el formato de hoja de vida (RevArq FP01); adicionalmente, se enviará el vínculo para la descarga de la versión digital.

También se enviará una constancia informativa en la que se relaciona la publicación del artículo y, de manera opcional, se pueden detallar las fechas del proceso editorial y el arbitraje realizado. 
La selección de revisores se realiza de acuerdo con los siguientes criterios:

- Afinidad temática.

- Formación académica.

- Experiencia investigativa y profesional.

- Producción editorial en revistas similares o en libros resultado de investigación.

El proceso de arbitraje se basa en los principios de equidad e imparcialidad, y en los criterios de calidad y pertinencia.

El desarrollo de la revisión se realiza según el formato (RevArq FP10 Evaluación de artículos) y las observaciones que el revisor considere necesarias en el cuerpo del artículo. En cualquiera de los conceptos que emita el revisor (Aceptar, Publicable con modificaciones, Reevaluable o No publicable), y como parte de la labor formativa y de comunidad académica, el revisor hará sugerencias para mejorar el documento. El revisor podrá solicitar una nueva relectura del artículo después de los ajustes realizados por el autor.

El revisor también deberá diligenciar el formato RevArq FP01 Hoja de Vida, con el fin de certificar y soportar el proceso de revisión ante los SIR que así lo soliciten.

En el proceso de arbitraje se emplea el método doble ciego, los nombres del revisor no serán conocidos por el autor y viceversa. Con el fin de garantizar el anonimato del autor, al artículo postulado se le han podido suprimir nombres, instituciones o imágenes que puedan ser asociadas de manera directa al autor.

Aunque se procura el anonimato, una vez recibida la invitación como par revisor del artículo, el revisor debe cerciorarse de que no exista conflicto de intereses (CDI) o alguna limitante que afecte la revisión o que pueda ser vista como tal (lazos familiares, amistad o enemistad, vínculos contractuales o laborales, posiciones éticas, etc.), de presentarse esta situación se notificara al editor. (Ver modelo RevArq FP06 CDI).

Dada la confidencialidad del proceso de revisión, y considerando los derechos de autor y de propiedad intelectual que pueda haber sobre el material que se entrega, el revisor se compromete a mantener en absoluta reserva su labor, a limitar el uso de la obra entregada solo para el propósito designado y a devolver la documentación remitida una vez concluya la actividad.

El tiempo establecido para las revisiones de pares es de máximo un mes a partir de la confirmación de la recepción de la documentación. Ese plazo podrá ser modificado de mutuo acuerdo entre el editor y el revisor, siempre y cuando no afecte la periodicidad de la revista, la impresión o el tiempo para emitir una respuesta al autor. Los revisores se acogerán a "COPE Ethical Guidelines for Peer Reviewers" de COPE.

\section{Beneficios}

Como retribución a los revisores se les hará envío postal de un ejemplar de la edición impresa sin ningún costo y entregada en la dirección consignada en el formato de hoja de vida. También, si es de interés para el revisor, podrá hacer la solicitud de alguna de las publicaciones editadas y presentes en el catálogo de publicaciones de la UNIVERSIDAD Católica de Colombia, previa aprobación de la Editorial y sujeto a la disponibilidad.

Si lo desea tendrá derecho a una constancia de la colaboración en la revisión de artículos, la cual solo contendrá el periodo en el cual se realizó la actividad. También tendrá la posibilidad de aceptar o no la publicación de su nombre, nacionalidad y nivel máximo de formación en la página web de la Revista de Arquitectura en su calidad de colaborador.

\section{(A) PROCESO DE REVISIÓN POR PARES}

Luego de la postulación del artículo, el editor de la Revista de Arquitectura selecciona y clasifica los artículos que cumplen con los requisitos establecidos en las directrices para los autores. El editor podrá rechazar en primera instancia artículos, sin recurrir a un proceso de revisión, si los considera de baja calidad o por presentar evidencias de faltas éticas o documentación incompleta.

Los artículos se someterán a un primer dictamen del editor, de los editores de sección y del Comité Editorial, teniendo en cuenta:

- Afinidad temática, relevancia del tema y correspondencia con las secciones definidas.

- Respaldo investigativo.

- Coherencia en el desarrollo del artículo, así como una correcta redacción y ortografía.
- Relación entre las figuras y tablas con el texto del artículo.

En esta revisión se verificará el nivel de originalidad mediante el uso de software especializado (Ithenticate o similar) y recursos digitales existentes para tal fin, también se observará la coherencia y claridad en los apartados del documento (método IMRYD), la calidad de las fuentes y la adecuada citación, esto quedará consignado en el formato (RevArq FP09 Revisión de artículos); esta información será cargada a la plataforma de gestión editorial y estará a disposición del autor.

En caso de que el artículo requiera ajustes preliminares, será devuelto al autor antes de ser remitido a revisores. En este caso, el autor tendrá veinte días para remitir nuevamente el texto con los ajustes solicitados.

Después de la preselección se asignan mínimo dos revisores especializados, quienes emitirán su concepto utilizando el formato (RevArq FP10 Evaluación de artículos) y las anotaciones que consideren oportunas en el texto; en esta etapa se garantizará la confidencialidad y el anonimato de autores y revisores (modalidad doble ciego).

Del proceso de revisión se emite uno de los siguientes conceptos que será reportado al autor:

- Aceptar el envío: con o sin observaciones.

- Publicable con modificaciones: se podrá sugerir la forma más adecuada para una nueva presentación, el autor puede o no aceptar las observaciones según sus argumentos. Si las acepta, cuenta con quince días para realizar los ajustes pertinentes.

- Reevaluable: cumple con algunos criterios y debe ser corregido. Es necesario hacer modificaciones puntuales y estructurales al artículo. En este caso, el revisor puede aceptar o rechazar hacer una nueva lectura del artículo luego de ajustado.

- No publicable: el autor puede volver a postular el artículo e iniciar nuevamente el proceso de arbitraje, siempre y cuando se evidencien los ajustes correspondientes.

En el caso de presentarse diferencias sustanciales y contradictorias en los conceptos sobre la recomendación del revisor, el editor remitirá el artículo a un revisor más o a un miembro del Comité Editorial quien podrá actuar como tercer árbitro, con el fin de tomar una decisión editorial sobre la publicación del artículo.

Los autores deberán considerar las observaciones de los revisores o de los editores, y cada corrección incorporada u omitida debe quedar justificada en el texto o en una comunicación adjunta. En el caso que los autores omitan las indicaciones realizadas sin una argumentación adecuada, el artículo será devuelto y no se dará por recibido hasta que no exista claridad al respecto.

El editor respetará la independencia intelectual de los autores y a estos se les brindará el derecho de réplica en caso de que los artículos hayan sido evaluados negativamente y rechazados.

Los autores, con su usuario y contraseña, podrán ingresar a la plataforma de Gestión Editorial, donde encontrarán los conceptos emitidos y la decisión editorial sobre el artículo.

El editor y el Comité Editorial se reservan el derecho de aceptar o no la publicación del material recibido. También se reservan el derecho de sugerir modificaciones de forma, ajustar las palabras clave o el resumen y de realizar la corrección de estilo. El autor conocerá la versión final del texto antes de la publicación oficial del mismo.

Cuando un artículo es aceptado para su publicación, el auto debe firmar la autorización de reproducción (RevArq FP03 Autorización reproducción). Para más información ver: Política de derechos de autor

\section{Notas aclaratorias:}

La Revista de Arquitectura publica un número limitado de artículos por volumen y busca el equilibrio entre las secciones, motivo por el cual, aunque un artículo sea aceptado o continúe en proceso de revisión, podrá quedar aplazado para ser publicado en un próximo número; en este caso, el autor estará en la posibilidad de retirar la postulación del artículo o de incluirlo en el banco de artículos del próximo número.

El editor y los editores de sección de la Revista de Arquitectura son los encargados de establecer contacto entre los autores y revisores, ya que estos procesos se realizan de manera anónima.

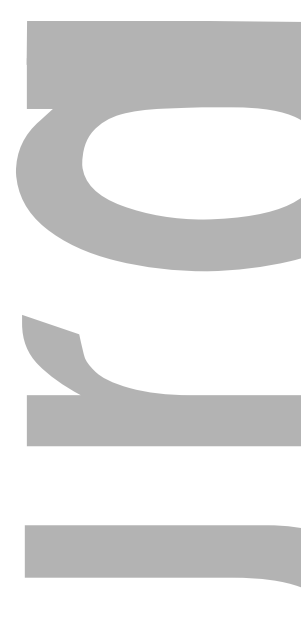

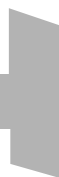
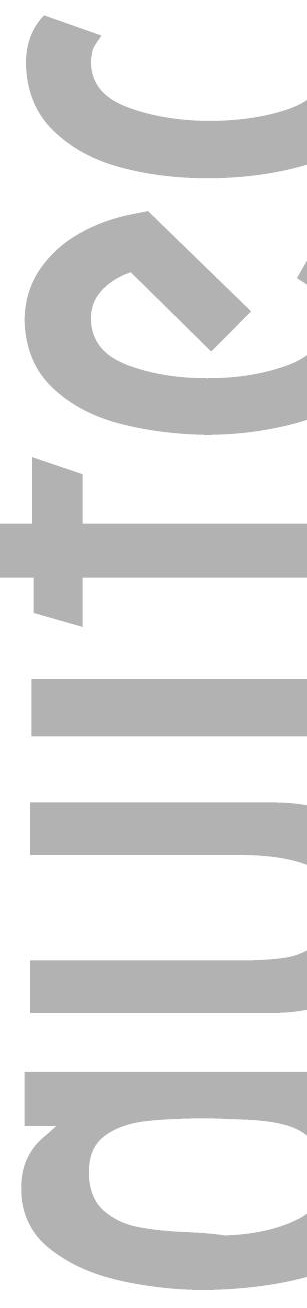

(2)

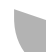

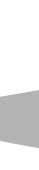

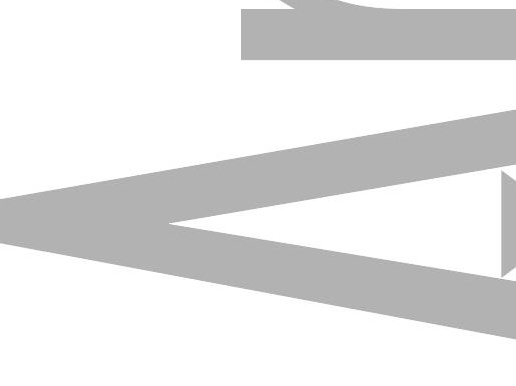


THE SOCIAL REPRESENTATION OF PUBLIC SPACE FOR THE DESIGN AND

MANAGEMENT OF SUSTAINABLE TERRITORIES

A THEORETICAL-PRACTICAL AND METHODOLOGICAL PROPOSAL FOR

PARTICIPATORY PLANNING

\section{Heidi Natalie Contreras-Lovich}

\section{PROPUESTA DE UN SISTEMA DE INDICADORES PARA EVALUAR}

PROPOSAL FOR A SYSTEM OF INDICATORS TO ASSESS THE VISUAL QUALITY OF

THE URBAN LANDSCAPE IN INFORMAL SETTLEMENTS

Johana Andrea Mesa Carranza, OsWaldo López Bernal.

Adriana Patricia López Valencia

Segregación EN EL ESPACIO URBANO de SOACHA

¿TRANSMILENIO COMO HERRAMIENTA INTEGRADORA?

SEGREGATION IN THE URBAN SPACE OF SOACHA

TRANSMILENIO AS AN INTEGRATING TOOL?

CARLos Augusto Moreno-Luna

\section{AROUITETURA E INDUSTRIALIZAÇÃO DAS CONSTRUÇÕES NA}

obra de JoÃo Filgueiras LIMA — LELÉ

ARCHITECTURE AND CONSTRUCTION'S INDUSTRIALIZATION IN THE WORK OF

JoĀo FilgueIrAs LIMA - LELÉ

Elza-Luli Miyasaka, Marieli Lukiantchuki, Michele C. B. Ferrari

CAIXETA, Marcio-Minto Fabricio

\section{EL DISEÑO DE LA VIVIENDA DE INTERÉS SOCIAL}

LA SATISFACCIÓN DE LAS NECESIDADES Y EXPECTATIVAS DEL USUARIO

THE DESIGN OF SOCIAL HOUSING

MEETING THE NEEDS AND USER EXPECTATIONS

Alex Leandro Pérez-PÉrez

EXPLORACIONES MORFOLÓGICAS EN TEXTURAS MODULARES

APROXIMACIONES DESDE EL OBJET TROUVÉ AL DISEÑO

نं PARAMÉTRICO

MORPHOLOGICAL EXPLORATIONS IN MODULAR TEXTURES

APPROXIMATIONS FROM OBJET TROUVÉ TO THE PARAMETRIC DESIGN

\section{CONSTRUCCIÓN EXPERIMENTAL DE UN SISTEMA}

